\title{
LA COOPERACIÓN INTERNACIONAL EN EL DERECHO DE LA TIC: HACIA UNA CARTA IBEROAMERICANA DE DERECHOS Y DEBERES DIGITALES ${ }^{1}$
}

\author{
INTERNATIONAL COOPERATION IN ICT LAW: TOWARDS AN IBERO- \\ AMERICAN CHARTER OF DIGITAL RIGHTS AND DUTIES
}

Daniel Enrique Rodríguez Suárez ${ }^{2}$

Universidad Rey Juan Carlos

\section{RESUMEN}

El presente artículo pone de manifiesto la importancia de establecer un modelo efectivo de gobernanza digital basado en derechos y responsabilidades por parte de los ciberusuarios. Ad portas de la cuarta revolución industrial; el reconocimiento de la existencia de una sociedad hiperconectada homo telecom y de los riesgos que se derivan de las actividades cotidianas, es el punto de partida para emprender un trabajo colaborativo, basado en el modelo de múltiples partes interesadas, y fundamentado en la capacidad que tiene la cooperación internacional a nivel regional, para hacer frente a los desafíos del derecho de las TIC en la era de la información. En ese sentido, se eleva una propuesta de construir, a nivel iberoamericano, un instrumento de soft law "Carta Iberoamericana de Derechos y Deberes Digitales CIDDI"; este instrumento tiene un alto componente ético, cultural y educativo, no exclusivo de la visión positivista clásica del derecho.

PALABRAS CLAVES: Cooperación internacional, Iberoamérica, gobernanza de internet, derecho digital, economía digital, gobierno electrónico, propiedad

\footnotetext{
${ }^{1}$ Artículo recibido el 27 de septiembre de 2019 y aprobado el 28 de octubre de 2019.

2 Profesional en Relaciones Internacionales de la Universidad Jorge Tadeo Lozano, Máster en Globalización, Comercio Internacional y Mercados Emergentes de la Universidad de Barcelona, Máster en Relaciones Internacionales Iberoamericanas de la Universidad Rey Juan Carlos, Estudiante de Doctorado en Ciencias Sociales y Jurídicas de la Universidad Rey Juan Carlos. Certificado en Digital Marketing and Community Management Trends por la Universidad de los Andes y en Contenidos Convergentes por el MINTIC y el Politécnico Grancolombiano. Ha sido Profesor de la Universidad Jorge Tadeo Lozano y Universidad Militar Nueva Granada. Es Director Ejecutivo de la Fundación Centro Iberoamericano de Estudios Internacionales CIBEI. Correo electrónico: d.rodriguezsu@urjc.es
} 
intelectual, ciberdelitos, carta iberoamericana de derechos y deberes digitales CIDDI.

\section{ABSTRACT:}

This article highlights the importance of establishing an effective model of digital governance based on rights and responsibilities on the part of the cyberusers. Ad portas of the fourth industrial revolution; the recognition of the existence of a hyperconnected homo telecom society and of the risks that derive from daily activities, is the starting point to undertake a collaborative work, based on the multi-stakeholder model, and based on the capacity that has international cooperation at the regional level, to face the challenges of the right of ICT in the information age. In that sense, a proposal to build, at the Ibero-American level, a soft law instrument "Ibero-American Charter of Digital Rights and Duties CIDDI". This instrument has a high ethical, cultural and educational component, not exclusive to the classical positivist vision of law.

KEYWORDS: International cooperation, Ibero-America, Internet governance, digital law, digital economy, electronic government, intellectual property, cybercrimes, Ibero-American charter of rights and digital duties CIDDI.

SUMARIO: INTRODUCCION. I. CONTEXTUALIZACIÓN DE LA COOPERACIÓN INTERNACIONAL IBEROAMERICANA. I.1. Retos en el marco de la Cooperación Iberoamericana. II. RESULTADOS. III. RECOMENDACIONES. III.1. Carta Iberoamericana de Derechos y Deberes Digitales CIDDI. III.2 ¿Por qué el sistema iberoamericano?. III.2.1. Actores involucrados - Modelo de Múltiples partes III.3 Aspectos sustantivos de la CIDDI. CONCLUSIONES

\section{INTRODUCCIÓN}

La globalización tecnológica ha conllevado a una transformación multidimensional de la sociedad internacional, entendida como "aquella sociedad global (macrosociedad) que comprende a los grupos con un poder social autónomo, entre los 
que destacan los Estados, que mantienen entre sí unas relaciones reciprocas, intensas, duraderas y desiguales sobre las que se asienta un orden común"3

Por lo tanto, "como fenómeno abarca indistintamente todas las manifestaciones de existencia de lo social y que, por ende, la globalización no debe asimilarse a una dimensión en particular"4. El avance tecnológico se presenta como uno de los campos de mayor prominencia en el proceso globalizador.

Las nuevas tecnologías de la información y las telecomunicaciones han conducido, a gran parte de la ciudadanía global, a encontrarse totalmente inmersos y dependientes de los sistemas de información, encargados de la obtención, análisis y procesamiento de datos a diferentes escalas a nivel internacional. La innovación tecnológica supone más que un fin un medio para cohesionar y afianzar el modelo imperante de globalización, la cual impacta al individuo en diferentes facetas. Una de ellas es a través de las nuevas formas de acceder a la información y al conocimiento. La sociedad de la información y conocimiento se establece como un nuevo paradigma que transciende de lo meramente económico a las relaciones sociales. "La información se constituye en uno de los "combustibles" que da vida a los distintos motores de la sociedad y que a su vez mueven a la sociedad"5

Cuando se trata el tema de las nuevas tecnologías necesariamente se piensa en su democratización, acceso, seguridad, impacto y regulación. Como afirma García (2015) "Hay que empezar por acceso, pero no hay que olvidar la importancia de reducir la brecha de conocimiento'(..)."’6. Esa reducción conduce al objetivo supremo de los gobiernos de elevar los índices de desarrollo humano. "Está demostrado que hay una correlación directa entre la penetración de internet, la apropiación de las Tecnologías de la Información y las Comunicaciones en la generación de empleo, reducción de pobreza y por ende la disminución del hambre"7.El conjunto de nuevas herramientas

3 CALDUCH CERVERA R. La Sociedad Internacional En: "Relaciones Internacionales". Editorial Ediciones Ciencias Sociales, Madrid, 1991, p.1.

4 VENGOA, FAZIO H. "La Globalización. Relaciones Internacionales, entre lo global y lo local". Ediciones TADEO. Bogotá,2004, Edición N 70, p.10.

${ }^{5}$ ALFONSO SÁNCHEZ, C. "La Sociedad de la Información, Sociedad del Conocimiento y Sociedad del Aprendizaje Referentes en torno a su Formación”. Bibliotecas Anales de Investigación, La Habana, 2016, $\mathrm{N}^{\circ} 2$, p. 236.

6 GARCÍA TERÁN, M. "TIC como un derecho humano". Tecnotool. 2015.Recuperado el 10 de noviembre de 2018 de https://tecnotool.com/tic-como-derecho-humano/

${ }^{7}$ RAMIREZ ROJAS, J. (2015). "Las tecnologías de la información y las comunicaciones - TIC - como herramientas de desarrollo económico y su impacto en la erradicación de la pobreza extrema y el hambre". Colegio Mayor Nuestra Señora del Rosario, Bogotá, 2015, p. 34. 
tecnológicas conforman lo que se denomina el "ecosistema digital". Dicho ecosistema puede entenderse

"Como el conjunto de prestaciones y requerimientos de diversa naturaleza que se proveen desde y a través de las redes de telecomunicaciones, el conjunto de infraestructuras y prestaciones asociadas que habilitan la prestación de dichos servicios, así como la interacción entre los prestadores de servicios de distinta naturaleza que constituyen la cadena de valor extendida de servicios de Internet, constituye un nuevo sujeto de análisis desde el que se debe pensar las políticas públicas"8.

La cooperación internacional entendida como el mecanismo mediante el cual los actores internacionales, principalmente Estados y organismos multilaterales, transfieren recursos técnicos, tecnológicos, financieros y know how para solventar una problemática específica. Al referirse al ecosistema digital, este ha de contemplarse como un conjunto de elementos de carácter tecnológico que viene a transformar la vida del hombre en sus diferentes facetas. ${ }^{9}$

\section{CONTEXTUALIZACIÓN DE LA COOPERACIÓN INTERNACIONAL IBEROAMERICANA}

La Cooperación Internacional ${ }^{10}$ en el entorno Iberoamericano se estructura principalmente a través del Convenio de Bariloche firmado en el año de 1995,y la construcción del Sistema Iberoamericano de Cooperación, que se conforma por organismos definidos que se han creado para generar un trabajo conjunto por parte de

\footnotetext{
${ }^{8}$ KATZ, R. (autor -coordinador) "El ecosistema y la economía digital en América Latina". Barcelona: Ariel, y Fundación Telefónica.2015, p XVII. Recuperado el 12 de noviembre de 2018 de http://www.fundaciontelefonica.com/arte_cultura/publicaciones-listado/paginaitempublicaciones/?itempubli $=430$.

${ }^{9}$ Ibíd., págs.399.

10 "La Cooperación Internacional ha basado su evolución histórica, en relaciones de amistad, de acciones conjuntas y alianzas estratégicas entre países, regiones, organismos e instituciones diversas. Ha sido una fuerza que ha permitido cultivarlas, permitiendo con ello recorrer, de manera conjunta, el camino del desarrollo institucional y el de sus pueblos" CASTRO, J. "Cooperación Internacional”, s/f. Recuperado el 20 de noviembre de 2018 de http:/www.ucipfg.com/Repositorio/MGTS/MGTS15/MGTSV1509/Unidad_academica/5/1_IntroCooperaci\%C3\%B3nInternacional.pdf
} 
diversos actores relevantes de sus países miembro ${ }^{11}$ para de tal forma facilitar el logro de objetivos comunes en ámbitos diversos; educación, seguridad social, juventud y gobierno, además de la creación de redes que trabajan en estos y otros temas, enriqueciendo la interacción y las acciones de la cooperación, temas que son canalizados en tres pilares 1) conocimiento, 2) cultura, 3) cohesión social, los cuales se fortalecen a través de las prácticas de Cooperación Sur- Sur que se implementan a nivel regional ${ }^{12}$.Todo ello con el fin de aumentar su alcance y efectividad, este tipo de relaciones en el ámbito internacional pueden clasificarse teóricamente como de interdependencia ${ }^{13}$. Con respecto a la Cooperación la Secretaría General Iberoamericana expresa:

"La misión de la Cooperación Iberoamericana es contribuir al desarrollo de la región iberoamericana a través de un modelo de hacer cooperación que la distingue de otros existentes y caracterizado por focalizar sus acciones en conseguir resultados concretos que incidan directamente en el fortalecimiento de las políticas públicas sectoriales nacionales"14.

La estructura de este sistema se compone de la Secretaría General Iberoamericana ${ }^{15}$ y de los Organismos de tipo Sectorial (Ver Figura 1) que configuran un importante espacio intrarregional que ha generado notorios avances a través de los instrumentos dispuestos para ello tales como programas enfocados en fortalecer la

\footnotetext{
11 Países que hacen parte del Sistema Iberoamericano de Cooperación: Andorra, Argentina, Bolivia, Brasil, Colombia, Costa Rica, Cuba, Chile, República Dominicana, Ecuador, El Salvador, España, Guatemala, Honduras, México, Nicaragua, Panamá, Paraguay, Perú, Portugal, Uruguay y Venezuela.

12 SECRETARÍA GENERAL IBEROAMÉRICANA, "La Cooperación iberoamericana", s/f. Recuperado el 23 de noviembre de 2018 de https://www.segib.org/cooperacion-iberoamericana/

${ }^{13}$ Hace referencia a relaciones de cooperación que generan un beneficio mutuo para las partes y que por tanto procuran el bienestar del otro lo que insta a superar con mayor facilidad las desavenencias que se puedan presentar. KEOHANE, R. y NYE, J. "Poder e Interdependencia; La Política Mundial en Transición”. Buenos Aires: GEL, 1998.

14 SECRETARÍA GENERAL IBEROAMÉRICANA, “¿Quiénes Somos?”, 2015, p.p.1-2. Recuperado el 22 de noviembre de 2018 de https://www.segib.org/quienes-somos/

15 Se define como un "espacio oficial de convergencia, trabajo, seguimiento, y acuerdos de la región iberoamericana que reúne países a ambos lados del Atlántico". Ibíd.

"La Secretaría General Iberoamericana (SEGIB) atendiendo a las funciones recogidas en su Estatuto, tiene el mandato de fortalecer y coordinar la Cooperación Iberoamericana. Para ello da seguimiento, apoyo y visibilidad a los Programas y realiza evaluaciones velando por su calidad y el impacto. Cada Programa es gobernado por un Comité Intergubernamental formado por representantes sectoriales de los gobiernos adheridos y cuenta con una pequeña Unidad Técnica que opera y ejecuta las acciones comunes". SECRETARÍA GENERAL IBEROAMÉRICANA. "Balance de la Cooperación Iberoamericana" s/f. Recuperado el 20 de diciembre de 2018 de https://segib.org/wpcontent/uploads/Balance-cooperacion-ib-castellano.pdf
} 
cooperación regional, gobernanza y medios de comunicación. Además de iniciativas en materia de innovación, redes de cooperación y proyectos adscritos, generando acuerdos que pretenden facilitar el afrontamiento de retos comunes por medio de la generación de herramientas que agilicen las acciones de mejora de la calidad de vida de los ciudadanos y permitan a los Estados hacer un trabajo más efectivo en cuanto a la garantía de los derechos de los mismos; resultados como convenios de cooperación judicial ${ }^{16}$.

\section{Figura 1.Sistema Iberoamericano De Cooperación ${ }^{17}$}

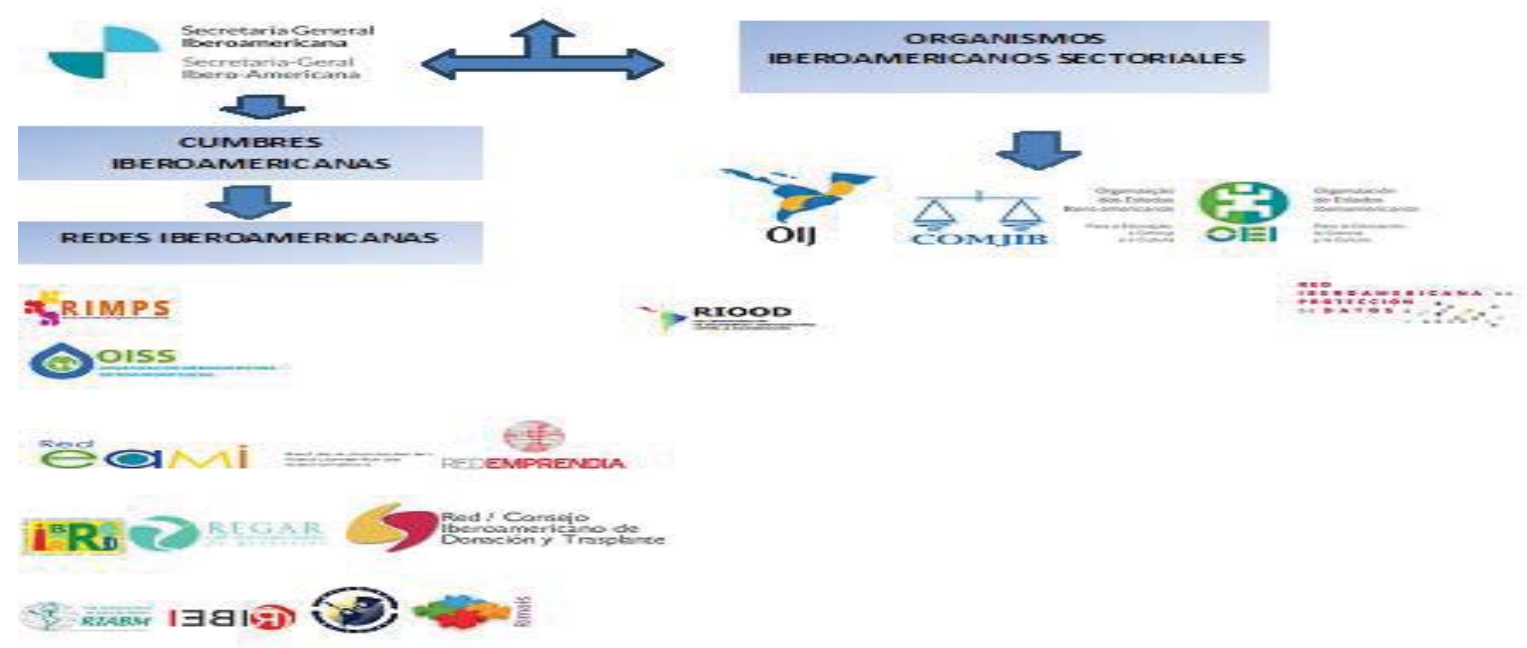

Algunos resultados a destacar del trabajo realizado en el marco de la Cooperación Iberoamericana se exponen a partir de diferentes temas, como se evidencia en la siguiente tabla:

Tabla 1. Resultados de la Cooperación Iberoamericana ${ }^{18}$

Tema Resultados

\begin{tabular}{l|l} 
Cultural & -Aproximadamente 1.300 producciones cinematográficas, algunas de
\end{tabular} ellas han obtenido galardones como el premio Oscar entre otros.

${ }^{16}$ Ibíd.

${ }^{17}$ Elaboración propia con información extraída de la SECRETARÍA GENERAL IBEROAMERICANA", La Cooperación Iberoamericana". 2018. Recuperado el 20 de diciembre de 2018 de https://www.segib.org/cooperacion-iberoamericana/

18 Elaboración propia con información literal obtenida de XXI CUMBRE IBEROAMERICANA PARAGAY 2011 \& SECRETARÍA GENERAL IBEROAMERICANA. 2011. "Anexo del Programa de Acción de Asunción Resultados de la Cooperación Iberoamericana- Resultados de los Programas, Iniciativas y Proyectos Adscritos de Cooperación Apoyados por la Cumbre Iberoamericana". Págs. 1-3. Recuperado el 25 de noviembre de 2018 de https://www.segib.org/wpcontent/uploads/Resultados_Programas_Anexo-PA-ESP.pdf 


\begin{tabular}{|c|c|}
\hline & $\begin{array}{l}\text { - Financiación por } 50 \text { millones de euros. } \\
\text {-Más de } 700 \text { ayudas brindadas a obras artísticas (teatro, danza y } \\
\text { diversos festivales a nivel regional). } \\
\text { - Una cifra que supera los } 400 \text { proyectos de gestión de archivo. } \\
\text { - Casi } 10 \text { proyectos relacionados con el fortalecimiento de las } \\
\text { políticas públicas hacia los museos, } \\
\text {-Otros proyectos para incentivar la conformación y difusión de las } \\
\text { orquestas juveniles. }\end{array}$ \\
\hline $\begin{array}{l}\text { Servicios } \\
\text { Sociales Básicos }\end{array}$ & $\begin{array}{l}\text {-Alimentación a aproximadamente } 150.000 \text { recién nacidos a traes de } \\
\text { mujeres voluntarias que donan su leche a Bancos de Leche Humana } \\
\text { provistos por el programa IBERBIT en el marco de la Cooperación } \\
\text { Iberoamericana. } \\
\text {-Una minimización superior del } 10 \% \text { de la tasa de analfabetismo en } \\
\text { la región. } \\
\text {-Aumento del acceso a la educación superior en un porcentaje que } \\
\text { supera el } 80 \% \text {. } \\
\text {-Más de } 700 \text { técnicos capacitados en gestión hídrica. }\end{array}$ \\
\hline $\begin{array}{l}\text { Municipalismo } \\
\text { y } \\
\text { Gestión } \\
\text { Territorial }\end{array}$ & $\begin{array}{l}\text {-Formación en Municipalismo a más de } 27.800 \text { alumnos. } \\
\text {-Creación del "Observatorio Iberoamericano de Políticas Públicas } \\
\text { Territoriales" } \\
\text {-Conformación de la "Red Universitaria Iberoamericana en Gestión } \\
\text { Territorial. }\end{array}$ \\
\hline $\begin{array}{l}\text { Espacio } \\
\text { Iberoamericano } \\
\text { del } \\
\text { Conocimiento }\end{array}$ & $\begin{array}{l}\text {-Más de } 8.000 \text { investigadores. } \\
\text {-Alrededor de } 1.280 \text { grupos de investigación. } \\
\text {-Más de } 55 \text { redes en materia de ciencia y tecnología. } \\
\text {-Publicación de más de } 400 \text { libros. } \\
\text { - Publicación de alrededor de } 3.800 \text { artículos científicos. } \\
\text { - A través del programa de movilidad académica, con la }\end{array}$ \\
\hline
\end{tabular}


participación de más de 150 beneficiados.

Calidad, Tic y -Participación de más de 11.800 personas en el programa de apoyo a Apoyo a las las PYMES.

PYMES - Creación de buenas prácticas de inclusión social en el marco de la utilización de las Tic por parte de las empresas.

\begin{tabular}{l|l}
$\begin{array}{l}\text { Fortalecimiento } \\
\text { de }\end{array}$ & $\begin{array}{l}\text {-Desarrollo de más de } 990 \text { proyectos de Cooperación Sur-Sur en el } \\
\text { ámbito Iberoamericano. } \\
\text { las }\end{array}$ \\
$\begin{array}{l}\text { Instituciones } \\
\text { Públicas }\end{array}$ & $\begin{array}{l}\text { Cooperación en el ámbito Iberoamericano. } \\
\text {-Creación del programa "Televisión Educativa y Cultural } \\
\text { Iberoamericana" por medio del cual se transmitieron más de } 4.000 \\
\text { horas de televisión. }\end{array}$
\end{tabular}

Según lo descrito, los instrumentos que se han implementado en la cooperación iberoamericana han permitido beneficiar a miles de ciudadanos de la región, en diversos temas que van desde la cultura hasta la capacitación, permitiendo la generación de herramientas para que mejoren su calidad de vida y aporten sus conocimientos a las comunidades en las que habitan.

\section{I.1. Retos en el marco de la Cooperación Iberoamericana}

Sin embargo los retos que enfrentan los países que conforman el Sistema Iberoamericano, en materia de cooperación son de gran envergadura, y más aun con el auge de la era digital, la cual ha traído consigo nuevas formas de interacción que facilitan el acceso a la Sociedad de la Información, el fortalecimiento de la libre expresión, la inmediatez de las transacciones comerciales, el teletrabajo, la sistematización de procesos entre otros beneficios para los usuarios, además "estimula directa e indirectamente el crecimiento económico de un país y contribuye al crecimiento del PIB y el empleo" ${ }^{19}$ pues la conectividad genera empleos, no solamente

19 MASON ANALYSYS. "Expansión de la Banda Ancha Moviel Eliminación de barreras para la expansión de la banda ancha movil a nivel subnacional". Buenos Aires: Corporación Andina de Fomento, 2017, pág. 14. 
desde la perspectiva de los usuarios que aprovechan el espacios virtual para laborar, sino desde una perspectiva externa, puesto que la infraestructura per se requiere personal de manera constante, además las empresas implementan otras formas de atención a sus clientes utilizando el internet y minimizando sus $\operatorname{costos}^{20}$

En la actualidad la conectividad ha permitido el desarrollo de la economía digital; algunas de las actividades que en ella se desarrollan son el comercio electrónico, teletrabajo, formación y capacitación a distancia, marketing digital, desarrollo tecnológico, el mercado de las criptomonedas, transacciones, inversiones entre otras.

Pero al mismo tiempo, esta cuarta revolución genera nuevas oportunidades a los delincuentes informáticos, para traspasar los límites de sus acciones al campo virtual y por ende transgredir los derechos de quienes navegan en internet.

Las nuevas tecnologías de la información y las telecomunicaciones han conducido, a gran parte de la ciudadanía global, a encontrarse totalmente inmersos y dependientes de los sistemas de información, encargados de la obtención, análisis y procesamiento de datos a diferentes escalas a nivel internacional. La innovación tecnológica supone más que un fin un medio para cohesionar y afianzar el modelo imperante de globalización, la cual impacta al individuo.

"Es indudable que las TIC han modificado nuestras actividades cotidianas $\mathrm{y}$, con ello, han potenciado nuestros derechos fundamentales, de tal manera que el derecho de acceso a la cultura puede materializarse de mejor manera gracias a las plataformas digitales. La cultura digital son las mismas dinámicas de relacionamiento, procesos culturales, creativos y consumos que hacemos en el mundo físico, pero llevadas al espacio virtual, en línea, mediadas por las TIC, generadas desde lo virtual y con especificidades propias del mundo digital". 21

Controlar las interacciones que dan cuenta de la cultura digital antes mencionada, no es una tarea fácil ni para los Estados, ni para los ciudadanos, porque la tecnología y la complejidad de lo que puede hacerse por medio de la red, crece a pasos

\footnotetext{
${ }^{20}$ Ibíd, págs. 306.

${ }^{21}$ SECRETARÍA GENERAL IBEROAMÉRICANA, "Recursos Digitales en Iberoamérica: una agenda accesible". XXI Cumbre Iberoamericana, La Antigua Guatemala 2018, pág. 6. Recuperado el 10 de enero de 2019 de https://www.segib.org/wp-content/uploads/Recursos-digitales-en-Iberoam--rica-ES.pdf
} 
agigantados y en opinión de algunos expertos, esta velocidad desborda la capacidad del derecho para realizar de manera ágil y con la especificidad requerida la definición, tipificación y pena adecuada para cada caso, pero más allá de ello, significa entonces que los Estados deben tener herramientas igual o más sofisticadas que con las que cuentan los ciberdelincuentes, para detectar, perseguir y aplicar las sanciones o penas debidas en cada caso, pues no basta con generar la regulación adecuada si no se tiene las herramientas para hacerla cumplir ${ }^{22}$.

De esta perspectiva puede inferirse que el derecho ya sea en el ámbito internacional o interno de cada Estado se ve limitado para abarcar todos los retos que la era digital implica, y que si bien la responsabilidad que en él recae es de grandes proporciones, no depende sólo de la parte jurídica el mantener seguros a los usuarios en la red, pues como sociedad global que en su generalidad amplía sus horizontes al ámbito virtual cada actor debe asumir su responsabilidad con respecto a los riesgos que asume al acceder de manera libre a la red.

Según un documento de la Cumbre Judicial Iberoamericana que versa sobre la ciberdelincuencia, en el ámbito regional países como Nicaragua y Uruguay, con respecto al "Derecho Penal Sustantivo" evidencian un vació normativo con respecto a la especificidad regulatoria de los delitos informáticos, por lo cual en dichos casos se aplica el derecho tradicional para procesar dichos delitos. Al respecto del "Derecho Procesal de Delincuencia Cibernética" sucede lo mismo siendo los países que mayores deficiencias presentan en tal disciplina, Venezuela, Honduras y Guatemala ${ }^{23}$

Por el contrario, hacen presencia en la región otros Estados que han desarrollado una línea normativa importante para regular las interacciones en el ámbito virtual, entre ellas los delitos informáticos tales como Brasil, Chile, España y República Dominicana. En cuanto a la aplicación de dichas leyes destacan República Dominicana, España,

\footnotetext{
22 JIMÉNEZ WILIAM, G \& MENECES QUINTANA, O. "Derecho e Internet; Introducción a un campo emergente para la Investigación y práctica Jurídica" Revista Prolegómenos Derechos y Valores", Bogotá,2017, No 40, pp.43-61.

23 CUMBRE JUDICIAL IBEROAMÉRICANA, "Estudio de Recomendaciones sobre Ciberdelincuencia" s/f, págs. 15. Recuperado el 30 de mayo de 2019 de https://www.google.com/search?q=ESTUDIO+DE+RECOMENDACIONES+SOBRE+CIBERDELINC UENCIA\&oq=ESTUDIO+DE+RECOMENDACIONES+SOBRE+CIBERDELINCUENCIA\&aqs $=$ chro me..69i57.658j0j7\&sourceid= chrome\&ie=UTF-8
} 
Brasil y México, los demás Estados de la región están en un proceso de evolución que les permita regular de manera exitosa el ámbito virtual ${ }^{24}$.

Como puede observarse existe una desigualdad jurídica con respecto a la regulación de los delitos informáticos y en general de las interacciones que llevan a cabo los usuarios en el ámbito virtual, por lo que es necesario además fortalecer la cooperación judicial, puesto que aunque existen los espacios necesarios para ello tales como la "Conferencia de Ministros de Justicia de los Países Iberoamericanos" (COMJIB) la cual se integra por los Ministros de Justicia de la región y que "tiene por objeto el estudio y promoción de formas de cooperación jurídica entre los Estados miembro" 25 , así como el

"Convenio Marco de Cooperación entre la Secretaría General Iberoamericana y el CONJIB que tiene entre sus puntos más relevantes la creación del "Convenio Iberoamericano de Cooperación sobre Investigación, aseguramiento y obtención de prueba en materia de ciberdelincuencia y recomendación de la Conferencia de Ministros de Justicia de los Países Iberoamericanos (COMJIB) relativo a la tipificación y sanción de la ciberdelincuencia"26

Sin embargo a pesar de la existencia de avances como el mencionado en lo que respecta a la cooperación entre los países iberoamericanos, es importante partir de que “estudios han señalado que los marcos jurídicos relacionados con la ciberseguridad y la ciberdelincuencia, de los diversos países de la región se encuentran aún en una etapa incipiente, en cuanto a la promulgación de leyes relacionadas con la materia"27

En este sentido es claro que jurídicamente por ejemplo no todos los países de la región están en capacidad de adherirse a los Convenios en materia de lucha contra la

\footnotetext{
24 Ibíd.

${ }^{25}$ ORGANISMO INTERNACIONAL DE JUVENTUD PARA IBEROAMÉRICA, “OIJ”. Recuperado el 20 de mayo de 2019 de https://oij.org/codei/

${ }^{26}$ CONFERENCIA DE MINISTROS DE JUSTICIA DE LOS PAÍSES IBEROAMÉRICANOS \& SECRETARÍA GENERAL IBEROAMÉRICANA. "Países iberoamericanos firman en Madrid convenio y recomendación sobre ciberdelincuencia". Recuperado el 20 de mayo de 2018 de https://www.segib.org/paises-iberoamericanos-firman-en-madrid-convenio-y-recomendacion-sobreciberdelincuencia/

${ }^{27}$ CUMBRE JUDICIAL IBEROAMÉRICANA, "Estudio de Recomendaciones sobre Ciberdelincuencia" s/f, pág. 2. Recuperado el 30 de mayo de 2019 de https://www.google.com/search?q=ESTUDIO+DE+RECOMENDACIONES+SOBRE+CIBERDELINC UENCIA\&oq=ESTUDIO+DE+RECOMENDACIONES+SOBRE+CIBERDELINCUENCIA\&aqs=chro me..69i57.658j0j7\&sourceid $=$ chrome $\& \mathrm{ie}=\mathrm{UTF}-8$
} 
ciberdelincuencia por ejemplo en el caso expuesto donde se hace referencia a la prueba electrónica, puesto que no todos los Estados iberoamericanos cuentan con herramientas jurídicas necesarias para cumplir con los requerimientos de cooperación que dicha disposición requiere. ${ }^{28}$

Esta situación puede presentarse en otros ámbitos que se relacionen con las interacciones virtuales, no solo con la ciberdelincuencia, pues el derecho debe tener los cimientos suficientes para regular diferentes ámbitos y determinar procesos específicos en otros temas como la educación, el gobierno electrónico, la propiedad intelectual, las criptomenedas, teletrabajo, comercio electrónico y en general todas las relaciones que se han construido en el ámbito virtual gracias al internet.

Pero esto solo es posible de manera integral si se evoluciona adecuadamente en la estructuración y continua actualización del derecho informático, el cual debe tener la capacidad de adaptarse a los retos que la tercera revolución de él demanda, y es menester por tanto que la cooperación jurídica genere prioritariamente herramientas que permitan a los países que presentan un desarrollo del derecho informático más incipiente, aprender de las experiencias exitosas de los Estados que han logrado adaptarse mejor y desarrollar de manera más sofisticada sus sistemas jurídicos para de tal forma hacer más eficiente la cooperación jurídica iberoamericana, con acciones que se reflejen en resultados concretos que se vean robustecidas al pasar el tiempo.

Otros retos que se presentan en el ámbito estudiado, versan sobre la infraestructura física que permite que las Tic funcionen adecuadamente, ya que similar a lo que sucede con las regulaciones en materia de derecho, existen muchas brechas a nivel regional.

Por ejemplo, con respecto al acceso a la telefonía móvil, países como Cuba con un acceso menor al cuarenta por ciento, mientras Ecuador y República Dominicana su porcentaje de acceso oscila entre el ochenta y el ochenta y cinco por ciento, mientras que otros Estados como Panamá, Costa Rica, Argentina y Uruguay superan el cien por ciento de accesibilidad, lo que se presenta, teniendo en cuenta que las personas en la actualidad pueden acceder a más de un dispositivo móvil, con respecto a las redes 4G y su capacidad de cobertura, se observa que Cuba, Nicaragua, Honduras, El Salvador y Venezuela no llegan al uno por ciento de cobertura y en otros casos más optimistas

\footnotetext{
${ }^{28}$ Ibíd., pgs. 15.
} 
como el de Ecuador, no alcanza a llegar al cincuenta por ciento o el de Costa Rica que apenas supera dicho porcentaje, ello contrasta con Uruguay y España que superan el ochenta por ciento de cobertura ${ }^{29}$

Estos son algunos ejemplos que dan cuenta de la brecha en materia de infraestructura en la era digital existente en la región, lo que afecta que puedan lograrse los objetivos comunes en materia de desarrollo Tic, puesto que son diferentes los avances en cada Estado especifico, y aunque algunos tienen similitudes, entre algunos existen diferencias que se ubican en ambos extremos de la medición especifica.

Por otra parte, en el ámbito de la ciberdelincuencia ${ }^{30}$ y la ciberseguridad ${ }^{31}$, las cuales hacen referencia a la ejecución de prácticas ilícitas en la red como en el primer caso y prevención o aplicación de estrategias tecnológicas para contrarrestar los delitos informáticos ${ }^{32}$ en el segundo, acciones tales como (ataques de tipo informático, acoso, sustracción de datos sin autorización, suplantación de identidad, entre otros) ${ }^{33}$.

En dichos temas todavía existen grandes vacíos que deben ser prioridad de las autoridades gubernamentales de cada Estado, aunque existen avances y se han creado espacios donde se trabajan estos temas y asuntos conexos, no se evidencia mucho dinamismo en este aspecto, a pesar de la existencia de estructuras permanentes que instan por fortalecer la cooperación judicial como el grupo "e- justicia" que en la

29 MASON ANALYSYS. "Expansión de la Banda Ancha Moviel Eliminación de barreras para la expansión de la banda ancha movil a nivel subnacional". Buenos Aires: Corporación Andina de Fomento, 2017, págs. 306

30 "Se entienden las «actividades delictivas realizadas con ayuda de redes de comunicaciones y sistemas de información electrónicos o contra tales redes y sistemas" DÍAZ DÍAZ, I. \& GRANADOS SAAVEDRA, M. "Ciberdelincuencia”. Ministerio de Justicia y Gracia. Costa Rica, s/f, pág.2.

31 "La ciberseguridad es el conjunto de herramientas, políticas, conceptos de seguridad, salvaguardas de seguridad, directrices, métodos de gestión de riesgos, acciones, formación, prácticas idóneas, seguros y tecnologías que pueden utilizarse para proteger los activos de la organización y los usuarios en el ciberentorno. Los activos de la organización y los usuarios son los dispositivos informáticos conectados, los usuarios, los servicios/aplicaciones, los sistemas de comunicaciones, las comunicaciones multimedios, y la totalidad de la información transmitida y/o almacenada en el ciberentorno". UNIÓN INTERNACIONAL DE TELECOMUNICACIONES, "Ciberseguridad" En: Actualidad de la UIT, haciendo referencia a la Resolución 181 del mismo organismo. 2010, pág. 20. Recuperado el 20 de mayo de 2019 de https://www.itu.int/net/itunews/issues/2010/09/pdf/201009 20-es.pdf

32 Se refiere a "todo acto o conducta ilícita e ilegal que pueda ser considerada como criminal, dirigida a alterar, socavar, destruir o manipular, cualquier sistema informático o alguna de sus partes componentes, que tenga como finalidad causar una lesión o poner en peligro un bien jurídico cualquiera". ACUARIO DEL PINO, S. "Delitos Informáticos: Generaliades". Recuperado el 20 de mayo de 2019 de https://www.oas.org/juridico/spanish/cyb_ecu_delitos inform.pdf

33 CONSEJO EUROPEO "Convenio sobre la Ciberdelincuencia Budapest - Serie de Tratados Europeos No 185”. Budapest, 2001. Recuperado el 30 de Mayo de2019 de https://www.oas.org/juridico/english/cyb pry convenio.pdf 
actualidad propone la construcción de una red que ejerza la cooperación en materia judicial con respecto a la ciberseguridad, de lo cual apunta que:

"En la actualidad es posible que los países miembros de cumbre efectúen las mismas pruebas y hasta cometan los mismos errores porque no están compartiendo información. Se propone la creación de una red de cooperación en materia de ciberseguridad entre los países miembros de la Cumbre Judicial Iberoamericana. La finalidad de esta red es crear un medio para que los especialistas en la materia de los diferentes países puedan compartir las mejores prácticas generando así una sinergia que evite, en la medida de lo posible, el desgaste de esfuerzos y que facilite la cooperación entre los miembros, y la socialización de experiencias con el fin de uniformar la fortaleza ante las amenazas cibernéticas" ${ }^{34}$

El apartado anteriormente citado claramente reconoce que aún existen falencias en materia de cooperación jurídica, con respecto a las interacciones que se presentan en la era digital, lo que retrasa el fortalecimiento de las herramientas conjuntas que permitan hacer más segura y eficiente la experiencia de los ciudadanos de la región iberoamericana en la red, de crearse el espacio de cooperación propuesto, se deben generar unos indicadores que permitan monitorear constantemente los resultados, además de implementar tecnología de punta con la autorización de los Estados que voluntariamente se acojan a dicha iniciativa, pues es necesario hacer cruces de información en tiempo real para ser capaces de detectar, identificar y enfrentar retos informáticos, que además no son estáticos, sino que por el contrario tienen gran capacidad y velocidad de evolución que solamente puede ser impactada con una verdadera disposición de cooperar, informar, intercambiar experiencias, invertir en investigación, y todas las directrices que sean necesarias.

El deber ser de la cooperación esta entonces en traspasar el escrito de los acuerdos, proyectos, iniciativas, etc., que son necesarios, pero solo revisten una verdadera importancia si se convierten en acciones, en cifras palpables, en resultados reales que se evidencien en la vida de los ciudadanos, de los niños y en general de las sociedades que integran los países iberoamericanos.

${ }^{34}$ SECRETARÍA PERMANENTE CUMBRE JUDICIAL IBEROAMÉRICANA “Ciberseguridad”.2017. Recuperado el 30 de mayo de 2019 de http://www.cumbrejudicial.org/e-justicia/ciberseguridad 
Es importante anotar además del derecho existen otras herramientas que complementan y jalonan hacia el deber ser las buenas prácticas en el ámbito virtual y hacen referencia al papel que cumplen los usuarios desde su rol no solo como internautas, sino como generadores de su propia seguridad y así como actores responsables de sus acciones establecen una relación más consecuente con las oportunidades y riesgos a los que pueden verse expuestos en el ámbito virtual.

Debe ser prioridad para los Estados generar políticas públicas que apunten a la concientización, por medio de la educación, acerca de las prácticas que deben implementar de manera preventiva cuando navegan por la red, además de dar a conocer a las comunidades las acciones que es menester realizar en caso de ser víctimas de uno o más de los múltiples delitos que pueden vulnerar sus derechos desde el internet, pues el reconocimiento de los delitos y la denuncia de los mismos, adicionalmente debe generarse un sentido de responsabilidad adecuado que enfoque a los usuarios a asumir un papel activo en el aprovechamiento de las Tic y en su propia seguridad desde una cultura de la prevención y de la acción hacia un entorno digital más amable para todos.

Es precisamente ese componente cultural el que se observa debilitado en las acciones que se implementan en el espacio de cooperación iberoamericano, puesto que es necesario establecer una interacción más constante con las comunidades y de tal forma generar un seguimiento adecuado que permita obtener la atención de la población, implementando estrategias de comunicación asertiva que además generen una motivación constante de los usuarios por aprender más acerca de la prevención y la autoprotección en internet, pero de tal forma que ese conocimiento se convierta en acciones concretas que los usuarios interioricen y repliquen en sus comunidades, en sus familias y en general con los actores que los rodean.

Aunque es claro que las campañas con respecto al conocimiento de los riesgos que las personas corren en internet, así como la difusión de las prácticas en materia de seguridad se hacen constantemente, es necesario crear estrategias que permitan generar una cultura que trascienda la difusión de información; la misma de la cual gran parte de las veces hacen caso omiso y que por tanto abre la puerta a los delincuentes informáticos que aprovechan la indiferencia que muchas personas manifiestan en la práctica, para cometer actos delictivos cada vez más difíciles de enfrentar; diversificando sus técnicas, a través del manejo inadecuado de tecnología 
progresivamente sofisticada, pero también aprovechando los vacíos con respecto a los conocimientos de las personas, o incluso a la falta de implementación de los conocimientos previamente adquiridos pero que por falta de concientización sencillamente no se llevan a la práctica.

\section{RESULTADOS}

Para corroborar lo anteriormente planteado, el autor del presente artículo realizó una encuesta en línea a ciudadanos de algunos países pertenecientes a la región Iberoamericana, seleccionando los participantes desde la técnica de muestreo no probabilístico; por conveniencia, teniendo en cuenta que los participantes fuesen usuarios de internet, sin limitar su edad, pero teniendo en cuenta que su país de origen o resida perteneciera a la región iberoamericana.

El instrumento se aplica con el objetivo de determinar los conocimientos que tienen los usuarios de internet con respecto a los delitos informáticos y establecer si llevan a cabo prácticas de seguridad en el entorno virtual para evitar ser víctimas de dichos delitos.

En tal sentido, la muestra que fue determinada por el investigador se compone de 105 participantes.

Algunas de las preguntas planteadas en la encuesta fueron las siguientes;

1.¿Sabe usted qué son los delitos informáticos?

A esta pregunta el $12.4 \%$ de los encuestados aseguro no tener conocimiento sobre el significado del término, contra $87.6 \%$ que afirmó si tenerlo, en este ítem se infiere que es alto el porcentaje de personas que no tienen claridad sobre los delitos informáticos, teniendo presente la importancia que reviste la era digital en la actualidad y los peligros a los que están expuestos los usuarios de la red.

Como segunda pregunta se planteó ¿Conoce sobre derecho de las TIC?

A está respuesta el $8.6 \%$ de los encuestados manifestó nunca haber tenido referencia de dicho término, este porcentaje se suma a un $40 \%$ que afirmaron no saber 
de qué se trataba, en comparación con el 51.4\% que admitió tener conocimiento sobre el tema.

La siguiente pregunta planteada fue; ¿Sabe a qué riesgos se expone al navegar en Internet?

En respuesta, el 6.7\% de los encuestados aseguro no conocer los riesgos a los que se enfrenta al navegar en internet, mientras el 93.3\% aseguró si conocer dichos riesgos.

Con respecto a la cuarta pregunta que reza: ¿Ha comprado en modalidad online con su tarjeta de crédito? Seleccione la opción más adecuada de acuerdo a su opinión; con respecto a ello, el $52.4 \%$ de los participantes aseguró si haber realizado compras en línea con tarjeta de crédito porque consideran que es una práctica que permite ahorrar tiempo, mientras que el 6.6\% expresa que lo hace porque lo considera seguro, mientras que el $26.7 \%$ no realiza compras por internet porque lo considera inseguro, mientras que el 14.3\% expresa no conocer el proceso para realizar las compras virtuales con su tarjeta de crédito.

A la siguiente pregunta ¿Ha sido víctima de saqueadores bancarios por Internet?. Los encuestados respondieron en un $86.7 \%$ respondieron que no, mientras el $13.3 \%$ aceptó serlo, aunque la cifra de personas que no han sido víctimas de este delito es positiva, todavía es relevante generar prácticas seguras por parte de los usuarios para reducir la cifra de las víctimas de este delito que en la muestra supera el 10\%.

Los anteriores, son algunos de los resultados más importantes de la encuesta realizada, que dan cuenta de que aún representa un reto el trabajo en materia de prácticas seguras en la red por parte de los usuarios, de prevención y concientización acerca de los peligros a los cuales se ven enfrentados a diario los usuarios en internet.

\section{RECOMENDACIONES}

Teniendo en cuenta el análisis antes proferido, a continuación se propone un instrumento de cooperación en materia digital, que se centra en el fortalecimiento de las voluntades de los Estados y de la participación de los ciudadanos desde la conciencia de un papel activo y responsable en la red, que mejore tanto el dinamismo de los 
ciudadanos como el compromiso de los Estados, para generar resultados crecientemente efectivos contra la ciberdelincuencia y en beneficio de los usuarios, haciendo cada vez más dinámicas y favorables sus interacciones en el ámbito virtual, desde un conocimiento adecuado desde el cual los diversos actores del entorno iberoamericano puedan insertarse de manera más responsable en la era digital para aprovechar todos su beneficios y disminuir las víctimas de sus peligros.

\section{III.1 Carta Iberoamericana de Derechos y Deberes Digitales CIDDI}

Apelando a uno de los principios primarios de la ordenación jurídica de una sociedad, en este caso la reconocida sociedad digital; el cual es la delimitación del ámbito espacial o limite espacial de la norma. "El territorio ha sido conceptuado, entre otras acepciones, para delimitar la aplicación y la eficacia de las normas jurídicas" ${ }^{35}$. Por lo tanto, se propone como punto de partida la necesidad de establecer unos referentes lindantes que permitan crear un espacio territorial trasfronterizo sobre el cual recaigan los derechos y las obligaciones derivadas del contrato. Para este objeto se hace referencia al "espacio iberoamericano"36.

Asimismo, acudiendo para este fin a un "nuevo corpus normativo digital"; el cual se promueve desde el fundamento de la extraterritorialidad "el ciberespacio no tiene fronteras y las relaciones, licitas e ilícitas entre diferentes sujetos tampoco"37 basado en la libertad de la red, se propone la creación de un instrumento de "soft law"38 que incluya los derechos y los deberes de los ciudadanos digitales.

\footnotetext{
${ }^{35}$ VELASCO RICO, C. "Territorialidad, extraterritorialidad e interés". INDRET Revista para el análisis del Derecho. Barcelona, 2011, pág. 5.

${ }^{36}$ El espacio iberoamericano hace referencia al sistema intergubernamental de integración de los países iberoamericanos, el cual tiene como principio "la comunidad es de todos". El espacio iberoamericano se compone de conferencias, encuentros, foros y una estructura administrativa en cabeza de la Secretaria General Iberoamericana SEGIB; como órgano permanente y de apoyo institucional. SECRETARÍA GENERAL IBEROAMÉRICANA, "SEGIB El Espacio Iberoamericano la Comunidad de todos", s/f, págs. 7.

37 ALMONACID LAMELAS, V. \& SANCLIMENT CASADEJÚS, X. "El impacto de las TIC en la configuración clásica del derecho. Especial referencia al principio de territorialidad". Revista Tecnología, Ciencia y Educación, No 4,2016, p.31.Recuperado el 30 de mayo de 2019 de file:///C:/Users/heidy/Downloads/Dialnet-ElImpactoDeLasTICEnLaConfiguracionClasicaDelDerech6159600.pdf

38 "El soft law en la teoría general del derecho se refiere a reglas de conducta, en este caso entre Estados, las cuales no tiene fuerza jurídica vinculante, aunque producen efectos relevantes". BALSSARE,P. "Soft Law y las Teorías de las Fuentes del Derecho". Soft Power. No 1,Ferrera, niversità degli Studi di Ferrara, p.75.
} 
Por consiguiente se conjugan los principios normativos de territorialidad y extraterritorialidad para el empeño de construir un instrumento internacional de ámbito regional que establezca un marco general aplicable a los países iberoamericanos; que además contribuya al logro de los Objetivos de Desarrollo Sostenible ODS en lo relativo a las nuevas tecnologías de la información y las comunicaciones y su imparto en el desarrollo humano. ${ }^{39}$

La necesidad de la carta de derechos y deberes digitales en Iberoamérica se fundamenta en los riesgos que se derivan de la actividad en el entorno digital. En ese contexto han de incorporarse en el objeto del acuerdo aspectos relacionados con los flujos de información de detalle y a gran escala "small data" y "big data" 40 , el tráfico de protección de datos personales, los delitos informáticos, la nueva economía digital, los derechos de autor y el gobierno en línea (actualizado). Todos estos fenómenos caracterizan a la sociedad de la información y del conocimiento del siglo XXI; cuyos pilares se moldearon sobre una base tecnológica. Según Ramos y Arévalo "fue McLuhan, quien en la década de 1960, «nos llevó a reflexionar sobre la plataforma tecnológica como determinante de una relación particular de la sociedad con las realidades a las cuales se estaba expuesto" 41 .

\section{III.2 ¿Por qué el sistema iberoamericano?}

Un primer aspecto que se debe señalar es que la arquitectura del internet, como parte de las Tecnologías de la Información y las Telecomunicaciones TIC, está compuesto por diversos actores que se ubican en diferentes lugares alrededor del mundo. Por ejemplo, un servidor puede estar ubicado en Estados Unidos (donde están la

\footnotetext{
${ }^{39}$ Los ODS reeamplazaron a los Objetivos de D"esarrollo del Milenio. Se estableció una agenda de los paises miembros de Naciones Unidas para el año 2030. Son 17 objetivos que están construidos sobre los tres pilares del desarrollo sostenible: económico, medioambiental y social. "La erradicación de la pobreza y la reducción de desigualdades- prioridades para América Latina y el Caribe-también son temas centrales en esta agenda que busca "no dejar a nadie atrás". COMISIÓN ECONÓMICA PARA AMÉRICA LATINA Y EL CARIBE (CEPAL), “Agenda 2030 para el Desarrollo Sostenible”.2019.Recuperado de https://www.cepal.org/es/temas/agenda-2030-desarrollo-sostenible

${ }^{40}$ El Small data y el biga data son conceptos que hacen referencia a la minera de datos. El primero tiene que ver con el detalle de la información sobre usuarios de la red, el segundo se aplica mayormente en contextos empresariales donde los volúmenes de información son muy altos.

${ }^{41}$ ARÉVALO TAPIA, M. \& RAMOS GRIJALVA, D. "La prevalencia de la sociedad del conocimiento o la sociedad de la información como elementos estructurantes del sistema social”. Prisma Social, Revista de Investigación Social, Universidad Católica del Ecuador, Quito,2018, No20, pág. 338.
} 
mayoría), mientras el proveedor de servicios se encuentra en México y el usuario en Colombia. Es una condición sobre la cual funciona el ciberespacio.

"El concepto de "universalidad de Internet" resalta algunos aspectos fundamentales e inmutables, como los derechos humanos, así como otros asuntos más fluidos y cambiantes, como el carácter de abierta y la accesibilidad. Como tal, el contenido del concepto debe conservar la flexibilidad y ser capaz de responder a los cambios $(\ldots)^{\text {,42 }}$

Esta cualidad lo que en definitiva permite es que exista un modelo de corresponsabilidad de múltiples partes interesadas. En esa misma línea la UNESCO advierte que

"La "universalidad de Internet" proporciona también un marco normativo útil para dar forma a procesos continuos para establecer marcos legales y modelos de negocio viables que impliquen al sector público y al privado, a la sociedad civil y a los responsables de formulación de políticas (...)” (UNESCO,2013:14).

Ahora bien, en términos pragmáticos, dichos modelos legales o derroteros pueden ser implementados desde los espacios regionales de cooperación internacional, bajo el amparo de la institucionalidad existente; para así establecer un mecanismo basado en un razonamiento inductivo que produzca resultados eficaces. Este supuesto se refuerza con la tesis del profesor Díaz Barrado; cuando se refiere a que los procesos de integración de los Estados latinoamericanos y del Caribe se caracterizan por su "carácter sumamente evolutivo" de forma paulatina y constante"43.

Desde luego, los procesos integracionistas latinoamericanos no se han distinguido por alcanzar a plenitud los logros originalmente propuestos. Tanto es así que existen procesos como el conocido como sistema andino de integración, antiguamente pacto andino, con cincuenta años de existencia; y hoy en día apenas subsiste. ${ }^{44}$

42 ORGANIZACIÓN DE LAS NACIONES UNIDAS PARA LA EDUCACIÓN, LA CIENCIA Y LA CULTURA (UNESCO) "Universalidad de Internet: un medio para crear sociedades del conocimiento y la agenda de desarrollo sostenible después de 2015". UNESCO, 2013, pág. 13. Recuperado de http://www.unesco.org/new/fileadmin/MULTIMEDIA/HQ/CI/CI/pdf/news/internet_universality_es_01.p df

${ }^{43}$ DÍAZ BARRADO, C. \& ROMERO MORETT, M. "Elementos de Análisis para la Integración de un Espacio Iberoamericano. Economía, Política y Derecho”. Plaza y Valdés. Madrid, 2008, pág. 109.

${ }^{44}$ La Comunidad Andina CAN es una organización internacional cuyo propósito principal es alcanzar un desarrollo integral, equilibrado y autónomo con miras a lograr una integración suramericana y 
En ese contexto, el mecanismo de integración iberoamericano constituye el escenario propicio para dar impulso a la carta de derechos y deberes digitales. El enfoque propuesto tiene un alto componente cultural y educativo, lo que coincide con los sectores de mayor avance en el seno de la comunidad iberoamericana. Por supuesto agregando, en palabras de Vera: "La historia compartida, con sus encuentros y desavenencias y las lenguas comunes, conduce a que sea lo cultural uno de los ámbitos en el que la colaboración ha sido y es más fluida y fructífera"45.

El reconocimiento de la existencia de una identidad iberoamericana basada en la cultura es uno de los valores más significativos, tal como lo expresa Díaz Barrado:

"La cultura es un elemento que asegura la identidad iberoamericana. Iberoamérica es una región con vocación de integración, al menos, en algunas de las dimensiones en las que se viene manifestando en los últimos tiempos el fenómeno de la integración en la escena internacional. Más allá de la integración política o económica, esta región reclama que se sienten las bases para la integración cultural."46

La institucionalidad es otro punto a favor. El sistema iberoamericano de integración tiene una amplia historia, se institucionalizó en el año 2003 cuando se crea la Secretaria General Iberoamericana SEGIB. ${ }^{47}$ A partir de ese momento, se fortalece el trabajo de las cumbres, conferencias y reuniones de los Estados que componen la comunidad. Su carácter cultural se refleja en dos de sus objetivos principales: "Promover los vínculos históricos, culturales, sociales y económicos entre los países iberoamericanos, valorando la diversidad entre sus pueblos". Y el segundo: "Implementar y fortalecer la cooperación sur-sur en la región, en las áreas prioritarias de educación, cultura y cohesión social"48.

latinoamericana. El acuerdo de Cartagena de 1969 es el instrumento fundacional de la CAN. COMUNIDAD ANDINA, “¿Qué es la Comunidad Andina?” 2019. Recuperado el 30 de mayo de 2018 de http://www.comunidadandina.org/Seccion.aspx?id=189\&tipo=QU\&title=somos-comunidad-andina 45 VERA JOSÉ, M, "Las cumbres y la cooperación iberoamericana". Razón y fe: Revista hispanoamericana de cultura, No 129-130,2009, pp. 63.

46 DÍAZ BARRETO, C. "Algunas reflexiones sobre la identidad en el seno de la Comunidad Iberoamericana de Naciones". Universidad Rey Juan Carlos. Revista Investigación y Desarrollo No 2, Madrid, 2013, pág. 428.

${ }^{47}$ La SEGIB es un organismo con personería jurídica internacional conformado por 22 países soberanos. Una de sus principales funciones es apoyar la organización de las cumbres iberoamericanas de jefes de gobierno y jefes de Estado. La secretaria general iberoamericana es la costarricense, Rebeca Grynspan.

48 SECRETARÍA GENERAL IBEROAMÉRICANA, ¿Quiénes Somos? Recuperado de https://www.segib.org/quienes-somos/ 
Sentado esto, también se debe resaltar la existencia de un conjunto de instrumentos internacionales, impulsados por la $\mathrm{CLAD}^{49}$, en concreto "cartas iberoamericanas" que sirven como antecedente, soporte y marco de referencia para ampliar la cooperación iberoamericana en lo referente al entorno digital. A continuación, se describen dichos instrumentos doctrinarios y su finalidad.

Tabla 2. Cartas Iberoamericanas ${ }^{50}$

\begin{tabular}{|c|c|c|}
\hline $\begin{array}{c}\text { Carta Iberoamericana de } \\
\text { la Función Pública }\end{array}$ & $\begin{array}{l}\text { Definir las bases que configuran un } \\
\text { sistema profesional y eficaz de función } \\
\text { pública (...) }\end{array}$ & Bolivia 2003 \\
\hline $\begin{array}{c}\text { Carta Iberoamericana de } \\
\text { Gobierno Electrónico }\end{array}$ & $\begin{array}{l}\text { Determinar las bases conceptuales y los } \\
\text { componentes que constituyen el } \\
\text { Gobierno Electrónico para } \\
\text { Iberoamérica. }\end{array}$ & $\begin{array}{l}\text { Santiago de } \\
\text { Chile, } 2007\end{array}$ \\
\hline $\begin{array}{c}\text { Carta Iberoamericana de } \\
\text { Calidad en la Gestión } \\
\text { Pública }\end{array}$ & $\begin{array}{l}\text { Promover un enfoque común en } \\
\text { Iberoamérica sobre la calidad y la } \\
\text { excelencia en la gestión pública, que } \\
\text { integre las distintas perspectivas } \\
\text { políticas y técnicas que se encuentran } \\
\text { presentes en los diversos niveles y } \\
\text { sectores de las Administraciones } \\
\text { Públicas de la región. }\end{array}$ & $\begin{array}{l}\text { El Salvador, } \\
2008\end{array}$ \\
\hline $\begin{array}{c}\text { Carta Iberoamericana de } \\
\text { Participación Ciudadana } \\
\text { en la Gestión Pública }\end{array}$ & $\begin{array}{l}\text { Fijar las bases conceptuales y los } \\
\text { componentes que constituyen la } \\
\text { participación ciudadana en la gestión } \\
\text { pública, como forma de mejorar la } \\
\text { calidad de las democracias en }\end{array}$ & Portugal, 2009 \\
\hline
\end{tabular}

49 El Centro Latinoamericano de Administración para el Desarrollo CLAD es un organismo intergubernamental, el cual se constituyó en el año 1972; cuyos miembros fundacionales fueron México, Perú y Venezuela. Su actividad principal está relacionada con la modernización de las administraciones públicas de sus 21 Estados parte.

${ }^{50}$ CENTRO LATINOAMÉRICANO DE AD MINISTRACIÓN PARA EL DESARROLLO - CLAD. "El Centro Latinoamericano de Administración para el Desarrollo, CLAD, es un organismo público internacional, de carácter intergubernamental”.2019. Recuperado el 31 de mayo de 2019. 


\begin{tabular}{|c|c|c|}
\hline & Iberoamérica. & \\
\hline $\begin{array}{c}\text { Carta Iberoamericana de } \\
\text { Gobierno abierto }\end{array}$ & $\begin{array}{l}\text { Definir las bases conceptuales y } \\
\text { prácticas que sustentan el gobierno } \\
\text { abierto como enfoque de gobernanza y } \\
\text { buen gobierno en el contexto } \\
\text { Iberoamericano. }\end{array}$ & $\begin{array}{l}\text { Colombia, } \\
2012\end{array}$ \\
\hline $\begin{array}{l}\text { Carta Iberoamericana de } \\
\text { los Derechos y Deberes } \\
\text { del Ciudadano en } \\
\text { Relación con la } \\
\text { Administración Pública }\end{array}$ & $\begin{array}{l}\text { Tiene como finalidad el reconocimiento } \\
\text { del derecho fundamental de la persona } \\
\text { a la buena Administración Pública y de } \\
\text { sus derechos y deberes componentes }\end{array}$ & Panamá, 2013 \\
\hline $\begin{array}{l}\text { Carta Iberoamericana de } \\
\text { ética e integridad en la } \\
\text { función pública. }\end{array}$ & $\begin{array}{l}\text { Promover la integridad de los } \\
\text { responsables y servidores públicos }{ }^{2} \text { en } \\
\text { todos sus niveles, entendiendo por tal } \\
\text { una actuación continuamente coherente } \\
\text { con los valores y principios relevantes } \\
\text { de la ética del servicio público. }\end{array}$ & $\begin{array}{l}\text { Guatemala, } \\
2018\end{array}$ \\
\hline
\end{tabular}

Elaboración propia con información obtenida del CLAD. ${ }^{51}$

Evidentemente la orientación de este compendio de recursos es el fortalecimiento de los sistemas de administración pública a cargo de los Estados firmantes, destacando el papel del ciudadano y sus derechos.

"Las Cartas Iberoamericanas elaboradas en el marco del CLAD son resultado de los consensos alcanzados por los gobiernos iberoamericanos en materia de buen gobierno y administración pública. Si bien abordan diversos temas, como los de la función pública, el buen gobierno, el gobierno electrónico, la calidad en la gestión pública y la participación ciudadana, el centro en ellas es el ciudadano y sus derechos. Su

\footnotetext{
${ }^{51}$ Las cartas iberoamericanas de la función pública y asuntos afines, son un instrumental muy valioso para los países de América Latina y la Península Ibérica. Su espíritu está abocado a proteger la importancia de la función pública transparente y eficiente, en un contexto mundial revolucionado por la aparición de las nuevas tecnologías de la información y las telecomunicaciones TIC. Las cartas merecen toda la atención y la publicidad necesaria para que se incorporen plenamente en el devenir de las instituciones públicas de los Estados Iberoamericanos.
} 
contribución a la teoría de la democracia, en el contexto Iberoamericano, es importante y merece ser conocido" 52 .

El instrumento que trata el tema de gobierno electrónico hace un aporte fundamental a la gobernanza digital del sector público, puesto que insta a los gobiernos a emprender un proceso de modernización en los servicios de atención al ciudadano bajo los postulados de transparencia, legalidad, eficiencia, eficacia y adecuación tecnológica. La crítica que se puede le hacer al documento es que se quedó corto en el esquema de supervisión de sus avances.

Con este panorama más claro, lo que se busca es aprovechar el tejido existente en cuanto a instrumentos y mecanismos de cooperación regional para conseguir una mayor eficacia en el proceso de implementación de la CIDDI. Finalmente de lo que se trata la cooperación internacional desde su propia definición, es de promover

$$
\begin{aligned}
& \text { “(..) acciones llevadas a cabo por los Estados Nación u } \\
& \text { organizaciones de éstos, actores subnacionales u ONGs de un país con } \\
& \text { otro/s de estos actores perteneciente/s a otro/s país/es, para alcanzar } \\
& \text { objetivos comunes en el plano internacional y/o en el nacional de uno } \\
& \text { o más actores." } 53
\end{aligned}
$$

Para este objetivo compartido, no es la cooperación financiera tradicional de los países desarrollados hacía los menos avanzados, la que más interesa. En cualquier caso, estaríamos más cerca de un modelo de cooperación técnica tipo cooperación Sur - Sur, la cual ha tenido en el concierto latinoamericano un gran desarrollo en los últimos tiempos. De acuerdo con el concepto de profesor Ayllon

$$
\begin{aligned}
& \text { "En realidad son múltiples las motivaciones que han llevado a los } \\
& \text { países de ALC a apostar decididamente por la CSS. Una revisión de } \\
& \text { los documentos oficiales, lineamientos y discursos de las autoridades } \\
& \text { gubernamentales permite afirmar que, por una parte, se enfatiza el } \\
& \text { discurso altruista de la CSS vinculado a identidades y valores, como }
\end{aligned}
$$

\footnotetext{
52 PIANA RICARDO. S, "Las Cartas Iberoamericanas para una Gestión Pública de Calidad. Orientaciones y buenas prácticas" En: Revista Aportes para la Integración Latinoamericana. 2010, Pág.23.

53 CHIANI ANA, M. (Coord); SCARTASCINI DEL RIO, J. (Coord). "La Cooperación Internacional: herramienta clave para el desarrollo de nuestra región”. Konrad Adenauer Stiftung: Buenos Aires. 2009, pág. 21.
} 
fruto de la existencia de desafíos similares, herencias compartidas, amistad con los vecinos, solidaridad regional e historia común". ${ }^{54}$

Las redes iberoamericanas existentes pueden ejercer un papel fundamental en esta tarea. En particular, La Red Iberoamericana de Protección de Datos (RIPD), la Red Iberoamericana de Estudios Internacionales (RIBEI) y la Red de Cooperación Jurídica Internacional (IBERRED). De igual manera, el registro de redes iberoamericanas, la cuales fueron creadas "Con el objetivo de fortalecer el espacio iberoamericano potenciando y favoreciendo la articulación de los distintos actores que realizan tareas significativas en las región (...." ${ }^{95}$ es una herramienta importante con miras a crear en un futuro próximo una red especializada en derechos y deberes digitales incorporando actores heterogéneos con intereses comunes.

Un aspecto de suma relevancia en el proceso de formación de la CIDDI es su carácter democrático, coincidente desde la esfera política con los sistemas de gobierno imperantes en Iberoamérica; y desde el punto de vista del ciberespacio igualmente como su principio rector desde su misma aparición.

“(..) en lo que se refiere a la relación existente entre Internet y democracia, entendiendo que el funcionamiento de la misma Internet o la "red" es democrático o propicia la democracia, al considerar que facilita a todo el que la maneja, en definitiva al que cuenta con un medio de acceso a la misma un conocimiento/poder/dominio sobre la realidad que antes no lo tenía: estaba reservado a quien había sido nombrado "gobernante" en el proceso de elección democrática de representantes políticos." ${ }^{, 56}$

Esta justificación se incorpora de manera explícita por dos razones fundamentales: en primer lugar, porque el propósito de la investigación y del presente

\footnotetext{
${ }^{54}$ AYLLON PINO, B. "La Cooperación Sur-Sur en América Latina y Caribe. De una época dorada a una fase incierta" En: Anuario de Integración 11. 2015, pág. 144.

Claramente el desarrollo del derecho digital es diferente en todos los países de la región. Lo importante para destacar es que regionalmente se está avanzando en cuanto a seguridad jurídica; principalmente en lo que respecta a protección de datos personales y derechos de autor. Los países con mayores avances, como el caso de España, están en una posición favorable para cooperar con los que apenas están en el camino regulatorio.

${ }^{55}$ SECRETARÍA GENERAL IBEROAMĖRICANA, "Registro de Redes Iberoamericanas", s/f, pág. .1. Recuperado de https://www.segib.org/wp-content/uploads/registro-redes-cast.pdf

${ }^{56}$ GALINDO AYUDA, Fernando, "Democracia, internet y gobernanza: una concreción". Sequencia (Florianópolis), No 64, 2012, pág., 34.
} 
escrito es poner de manifiesto la urgencia que existe respecto a establecer una gobernanza en internet que promueva y proteja los derechos humanos de los usuarios "ciudadanos iberoamericanos" y de la misma manera le brinde seguridad a todos los actores que hacen parte del ecosistema digital. ${ }^{57}$ En segunda medida, la legitimación de cualquier constructo normativo tiene que pasar por la aportación colectiva, esto es, son las múltiples partes involucradas; quienes deber ser partícipes de la negociación. En el fondo lo que se busca, a través de este recurso, es brindar unas directrices que se deben considerar durante todo el proceso participativo de creación de la CIDDI.

\section{III.2.1. Actores involucrados - Modelo de Múltiples partes}

Habitualmente el esquema de formación de una norma de carácter internacional le asigna una responsabilidad exclusiva a los actores estatales, propiamente al Estado. Desde luego, la ordenación jurídica desde la esfera pública se ha construido a partir de la existencia de la sociedad internacional que a su vez está compuesta por diversas sociedades nacionales (existencia de pluralidad de actores). Sin embargo, "cuando se relacionan mediante el Derecho Internacional Público solo se consideran aquellos sujetos que los propios creadores del DIP han definido como tales, primordialmente estados y las organizaciones internacionales en sus ámbitos específicos de acción"58.

Indudablemente no se trata de restarle importancia a la competencia que tiene el Estado en los asuntos de política internacional. Al contrario, por su personalidad jurídica y su capacidad institucional sigue siendo el principal actor y el epicentro a partir de cual se pueden conseguir objetivos que beneficien a la sociedad. De lo que trata el argumento acá expuesto es de extrapolar la "capacidad jurídica” hacia todos los actores

\footnotetext{
${ }^{57}$ El ecosistema digital o ecosistema de internet hace referencia la interconexión de tres capas: la capa de infraestructura, la capa lógica y la capa social y económica. Estas capas a su vez estas compuestas por diferentes actores “( $(.$.$) organizaciones y comunidades que ayudan a la labor y evolución de internet”. La$ característica más relevante es la deslocalización de dichos actores. En términos generales todas las personas con acceso a la red somos parte del ecosistema digital. CASTRO, A. "Gobernanza en Internet". Universidad Externado de Colombia. Recuperado el 31 de mayo de 2019 de https://miriadax.net/web/gobernanza-deinternet/reto?p_p_id=activityViewer_WAR_liferaylmsportlet $\& p \_p \_$lifecycle $=0 \& p \_p \_s t a t e=n o r m a l \& p \_p$ mode $=$ view\&p p col id $=$ column-

$1 \& p \_p \_c o l \_p o s=2 \& p \_p \_c o l \_c o u n t=3 \& p \_r \_p \_564233524 \_$act $d=197720 \& p \_r \_p \_564233524$ moduleId $=$ 82331\&p

58 BENAVIDES CASALS, M. "La Construcción del Derecho Internacional, el sueño de un reducto jurídico occidental”. Revista Colombiana de Derecho Internacional, No 28, Bogotá 2016, pág. 20.
} 
involucrados en el entorno digital; y no solo desde el punto de vista obligatorio, sino también desde la perspectiva autónoma y voluntaria del individuo. ${ }^{59}$

Los organismos internacionales también han emprendido acciones importantes para fortalecer la seguridad jurídica en internet. Vale la pena destacar la reciente celebración de la primera "Conferencia sobre Contextos Jurídicos de Economía Digital en Latinoamérica”. Una iniciativa promovida por la Organización de Naciones Unidas y el Ministerio de Tecnologías de la Información y Comunicaciones de Colombia MinTic. La Ministra de la cartera, Silvia Constaín, se refirió al evento argumentando que:

"La tecnología es un fenómeno mundial que evoluciona con rapidez y de forma constante. Por eso, es importante que los estados actualicemos periódicamente los textos sobre comercio electrónico. Actualmente, a más de 70 países, incluido Colombia, nos cobija un marco jurídico de utilización de medios electrónicos o comercio electrónico que debe ser socializado, debatido y actualizado" (MINTIC, 2019, ONU y MinTIC organizan primera conferencia sobre contextos jurídicos de Economía Digital en Latinoamérica) ${ }^{60}$

Este espacio de disertación sobre los asuntos que atañen a la economía digital en la región en sus aspectos regulatorios viene a complementar el trabajo de otras organizaciones del Sistema de Naciones Unidas y de la propia Organización para la Cooperación y Desarrollo Económico OCDE en sus estudios sobre políticas y regulación de las nuevas tecnologías. ${ }^{61}$

\footnotetext{
59 Por ejemplo, en el caso de los menores de edad, que son actores ubicados en una zona de alta vulnerabilidad en contextos digitales como las redes sociales, la Corte Constitucional colombiana se refiere a que su capacidad jurídica se encuentra fundamentada en su aptitud de ser sujeto de derechos, como titular de prerrogativas, los cuales requieren una protección especial o reforzada de sus derechos. CORTE CONSTITUCIONAL DE COLOMBIA, "Capacidad Jurídica, Capacidad de Derecho o de Goce, Capacidad de Hecho o de Ejercicio - Sentencia C-534/05".2005. Recuperado de http://www.corteconstitucional.gov.co/relatoria/2005/C-534-05.htm

${ }^{60}$ MINISTERIO DE LAS TECNOLOGÍAS DE LA INFORMACIÓN Y LA TELECOMUNICACIÓN, "ONU y MinTIC organizan primera conferencia sobre contextos jurídicos de Economía Digital en Latinoamérica"2019. Recuperado el 07de junio de 2019 de https://www.mintic.gov.co/portal/604/w3article-101006.html

La Conferencia fue celebrada en la ciudad de Bogotá el 05 de junio de 2019 bajo el auspicio de la Comisión de las Naciones Unidas para el Derecho Mercantil Internacional CNUDMI. Sirvió como encuentro de expertos diferentes países, quienes discutieron principalmente temas relacionados con los contratos inteligentes y la tecnología de Blockchain y la inteligencia artificial.

${ }^{61} \mathrm{La}$ OCDE ha reconocido la emergente y progresiva importancia del sector TIC para aumentar la productividad y por ende el crecimiento económico de las naciones. Adicionalmente, como una
} 
En términos específicos, y de manera integral, el modelo de múltiples partes interesadas o multistakeholders aplicable en la creación de la CIDDI estaría representando de la siguiente manera:

\section{Grafico 1. Modelo de múltiples partes interesadas ${ }^{62}$}

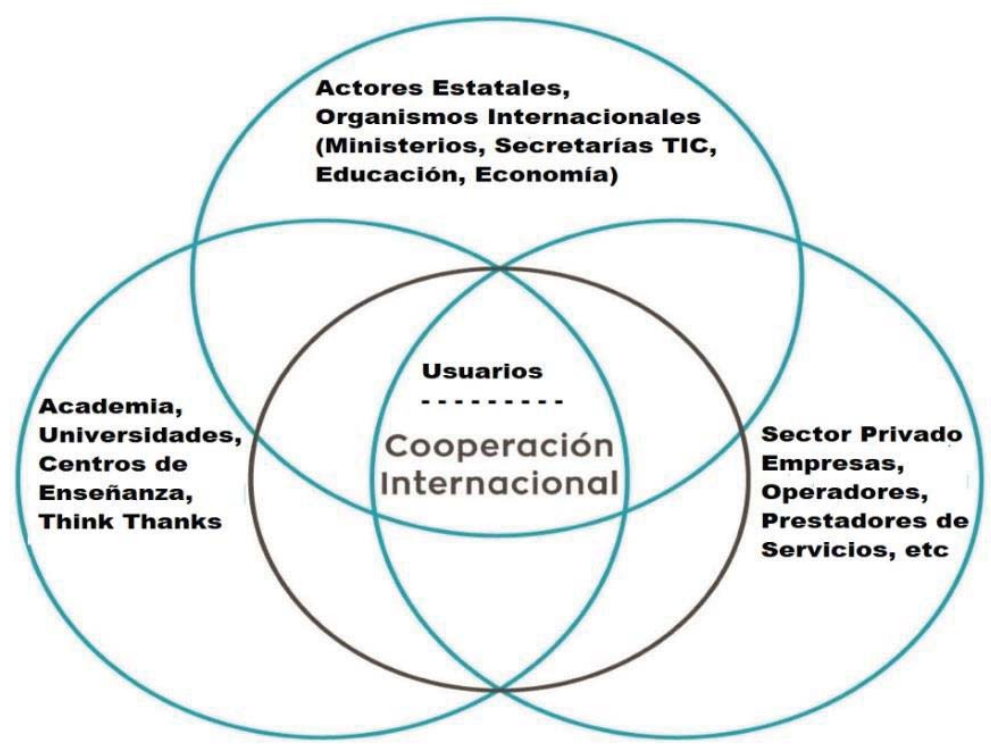

Fuente: elaboración propia con información del "los mecanismos de gobernanza de internet" de la IS.

\section{INTERNET SOCIETY 63}

Como se observa el eje central del modelo es el usuario, esto es, el ciudadano digital. Como ya se ha advertido suficientemente es el titular indiscutible de los derechos y obligaciones en un universo complejo llamado internet. Aun así, es pertinente advertir que "El enfoque de múltiples partes interesadas es una caja de herramientas, no una solución única" ${ }^{\text {64 }}$. El derecho educativo, en esta propuesta, realiza un aporte fundamental que se traslapa al plano cultural. "La educación en sí misma, se

oportunidad para que los gobiernos aumenten la calidad de los servicios públicos prestados por sus instituciones.

62 Elaboración propia con información del INTERNET SOCIETY, “Gobernanza de Internet: Por qué funciona el enfoque de múltiples partes interesadas". 2016.Recuperado de https://www.internetsociety.org/wp-content/uploads/2016/04/IG-MultiStakeholderApproach-ES.pdf

${ }^{63}$ En el centro del modelo aparece el mecanismo de "cooperación internacional”. Esta la vía propuesta para alcanzar un desarrollo significativo en la gobernanza de internet y en términos amplios en el ciberderecho. De igual manera, se incluyen la multiplicidad de actores de origen público y privado que comparten intereses y preocupaciones comunes. A este esquema tripartito, que incluye a la academia con un papel fundamental, le compete la toma de decisiones frente a los riesgos derivados de una sociedad internacional hiperconectada.

${ }^{64}$ INTERNET SOCIETY, "Gobernanza de Internet: Por qué funciona el enfoque de múltiples partes interesadas". 2016, pág. 1. Recuperado de https://www.internetsociety.org/wpcontent/uploads/2016/04/IG-MultiStakeholderApproach-ES.pdf 
sitúa en el ámbito de la cultura, ya que la educación representa el proceso de transmisión de la cultura a las sucesivas generaciones" ${ }^{\prime 65}$.

\section{III.3 Aspectos sustantivos de la CIDDI}

Las principales cuestiones que en estos momentos, en vertiginosa evolución, merecen una especial atención en acciones de gobernanza efectiva y seguridad jurídica en el medio digital, son los siguientes.

Protección de datos personales: "Los datos son el bien más preciado y producido de la sociedad" (MOLANO, 2019). Por eso han sido consideraros por la economía moderna como uno de factores claves del desarrollo. Del mismo modo, los datos son el eje central de las discusiones en torno a los modos de protección y regulación de las actividades que desarrolla el individuo en el ciberespacio. En ese sentido, su protección deberá ser una piedra angular del instrumento propuesto para las naciones iberoamericanas.

En el plano internacional se han hecho avances importantes frente a la protección de datos de carácter personal. El nuevo reglamento europeo de protección de datos, también conocido como el reglamento general de protección de datos RGPD es un salto enorme a nivel regulatorio, el cual pretende tener implicaciones a nivel extracomunitario. ${ }^{66}$ Nace con la necesidad de realizar una reforma de gran calado en la normativa comunitaria para elevar en la Unión Europea la exigencia legal de esta materia tan importante en la nueva "sociedad del dato" 67.

Su proceso de elaboración y principalmente de difusión y adaptación sirven como referente para tener en cuenta a nivel iberoamericano; por supuesto sin

${ }^{65}$ SORIA VERDERA, Raúl, "El Derecho Educativo en el Mundo Jurídico". Libook: Catamarca. 2013, pág. 3.

${ }^{66}$ El RGPD (2016/679) entró en vigor en el 2016 y con plena aplicación en el año 2018. Esta normativa regula el tratamiento que realizan las empresas, organizaciones y personas de datos personales en la Unión Europea. (COMISIÓN EUROPEA, 2019) El reglamento incorpora un alcance extracomunitario para los servicios que se presten desde otros países a los ciudadanos europeos. Al mismo tiempo establece un mecanismo tipo "Privacy Shield Framework" que funciona como una red de cooperación con Estados Unidos y Suiza para los casos de transferencias transfronterizas de datos Personales. COMISIÓN EUROPEA, ¿Qué rige el reglamento general de protección de datos? (RGPD). La comisión y sus prioridades, políticas información y servicios. 2019.Recuperado el o7 de junio de 2019 de https://ec.europa.eu/info/law/law-topic/data-protection/reform/what-does-general-data-protectionregulation-gdpr-govern es

67 ORTEGA GIMÉNEZ, A \& DOMENECH GONZALO J. "Nuevo marco jurídico en materia de protección de datos de carácter personal en la Unión Europea". Revista Facultad de Derecho No 44. Montevideo, 2018, pág. 4. 
desconocer los avances normativos nacionales y comunitarios de los Estados Iberoamericanos.

Al tiempo que se debe destacar el instrumento existente con el espacio iberoamericano conocido como "Estándares de Protección de Datos para los Estados Iberoamericanos", el cual es un importante insumo para construcción de la CIDDI. ${ }^{68}$ Estos estándares buscan, entre otros propósitos: "Establecer un conjunto de principios y derechos de protección de datos personales que los Estados Iberoamericanos puedan adoptar y desarrollar en su legislación nacional, con la finalidad de garantizar un debido tratamiento de los datos personales y contar con reglas homogéneas en la región" ${ }^{69}$.El mismo instrumento contempla mecanismos complementarios de cooperación internacional. España, en su experiencia como miembro de la UE puede aportar significativos aprendizajes.

Tal como se advirtió, la protección de datos personales es el leitmotiv de la propuesta de establecer un conjunto de derechos y deberes para los actores de la era digital dada su transversalidad en todas actividades realizadas en la red. Además de su suprema categoría como miembro de la familia de los derechos humanos. En la mayoría de las constituciones incluido como derecho fundamental. "El $70 \%$ de los países latinoamericanos incorporan en su Constitución disposiciones explícitas referentes a aspectos relacionados con la protección de datos personales"70. Por tanto, La promoción y defensa de este derecho humano (protección de datos de carácter personal) consolida las libertades que son necesarias en un Estado Constitucional y Democrático de Derecho"71 .Como lo son actualmente la gran mayoría de los Estados Iberoamericanos.

\footnotetext{
${ }^{68}$ En el año 2017 en Cartagena, Colombia, se aprueban los "Estándares de Protección de datos para los Estados Iberoamericanos". Este logro representa una herramienta fundamental para la estrategia de la Red a nivel regional; y como referente para futuros desarrollos normativos. RED IBEROAMÉRICANA DE PROTECCIÓN DE DATOS "Estándares de Protección de Datos Personales para los Estados Iberoamericano" 2017, pág. 12. Recuperado el 07 de junio de 2019 de http://www.redipd.org/noticias_todas/2017/novedades/common/Estandares_Esp_Con_logo_RIPD.pdf\#Te sto $\% 20$ en $\% 20$ espa $\%$ C $3 \% \mathrm{~B} 1$ ol

${ }^{69}$ Ibíd., pág. 12.

${ }^{70}$ REMOLINA ANGARITA, N. (s/f). "Latinoamérica y Protección de Datos Personales en Cifras (19852014)". Universidad de los Andes. Bogotá, s/f, pág. 1. Recuperado el 10 de junio de 2019 de https://habeasdatacolombia.uniandes.edu.co/wp-content/uploads/2014-Latinoamerica-proteccion-datosen-cifras-1985-2014-Remolina.pdf

${ }^{71}$ RICHER, M. "La Protección de Datos de Carácter Personal como Derecho Humano". Revista Auctoritas Prudentium, №. 12, 2015, pág., 18.

Interamericano de Estudios de Seguridad Social (CIESS), Guatemala, 2015, pág. 18.
} 
Uno de sus principales retos consiste en establecer disposiciones efectivas que disminuyan los riesgos en las transferencias internacionales de datos personales, garantizando la cadena de protección de los mismos.

"Esta regla se conoce como el principio de continuidad de la protección de datos, el cual se fundamenta en que "la transferencia internacional de datos no debe afectar la protección de los interesados por lo que respecta al tratamiento de sus datos personales"72 (REMOLINA \& ALVAREZ, 2018:27)

Economía Digital: El impacto de la sociedad de la información y del conocimiento se ha reflejado en todas las áreas en donde la interrelación entre individuos se hace presente. Como lo afirma Valdés: "Estamos en una era diferente a la que conocemos. El gran cambio lo está marcado la transición del paradigma de la sociedad industrial al paradigma de la sociedad del conocimiento" (BUSTOS, s/f: 4). Las TIC han traído consigo un nuevo concepto frente a los intercambios de bienes y servicios: la economía digital. Este novedoso paradigma económico surge de la transformación que atrae la denominada "cuarta revolución industrial" como un fenómeno de alcance global. ${ }^{73}$

Cuando Guillermo Corredor afirma que:

"Las propuestas regulatorias en torno al concepto de economía digital o economía de los datos constituyen un tema principal dentro de la agenda económica de los países industrializados" ${ }^{74}$ excluye los países de economías emergentes, como en caso de América Latina; la agenda global económica indiscutiblemente comprende la nueva economía. Además, lo cierto es que la economía digital como fenómeno universal crece mucho más de prisa que la economía tradicional. Esto lo corrobora el Banco Interamericano de Desarrollo al revelar que para el año 2017 “el valor de la economía digital tiene un valor de US \$ 11.5 billones, equivalente al 15.5\% del PIB mundial, y

72 ALVÁREZ, L \& REMOLINA, N., "Guia GECTI para la implementación del principio de responsabilidad demostrada -accountability- en las transferencias internacionales de datos personales". Universidad de los Andes, Facultad de Derecho GECTI.Bogotá,2018, pág.27.

${ }^{73}$ La Cuarta Revolución Industrial hace referencia a un nuevo periodo económico que apenas surge en el siglo XXI, en el cual tecnologías como la inteligencia artificial, el blockchain, la robótica, el big data, entre otras, suponen un cambio estructural en las estructuras económicas; y por supuesto en la vida de las personas.

${ }^{74}$ CORREDOR CASTEllanOS, G. “Consolidación de la Economía Digital y Desafíos en materia de protección de la privacidad". Revista de Derecho, Comunicaciones y Nuevas Tecnologías, Universidad de los Andes, Bogotá, No 14, 2015, pág. 4. 
estima que para el año 2025 representará entre US \$ 23 y US \$ 24 billones del PIB mundial"75 (Banco Interamericano de Desarrollo - BID, 2017:1).

Los agentes económicos, proveedores de servicios de internet, compañías del sector TIC, la banca, y en general empresas públicas y privadas que intervienen en la prestación y compraventa servicios y mercancías a través de canales digitales (comercio electrónico), están en el deber de construir e implementar políticas que brinden seguridad y protección a los usuarios, o clientes. Por esta razón, el sector empresarial de compañías iberoamericanas, bajo el modelo imperante e imperfecto de "autorregulación" comprende una arista importante en el consenso para alcanzar la CIDDI.

La economía digital presenta otro desafío importante para los países del espacio iberoamericano, el cual consiste lograr una sinergia en los sistemas nacionales de tributación para reducir la evasión fiscal. "Esta situación genera tensiones entre los países intervinientes pues no existe aún consenso respecto a qué jurisdicción tiene derecho a gravar tales rentas, ni sobre la calificación jurídica de las operaciones ejecutadas" (SANIN, 2015: 233). Una vez más la dimensión cultural del acuerdo de derechos y deberes digitales va a jugar un papel trascendental para este propósito.

El sector financiero también es un jugador importante. Las criptomonedas como el bitcoin, creadas bajo la tecnología del blockchain, han alcanzado un auge indiscutible en tiempos recientes. ${ }^{76}$ Coincidiendo con Auer:(...) aunque los criptoactivos no representen en este momento un riesgo para la estabilidad financiera mundial, es importante permanecer vigilantes, realizar un seguimiento de los acontecimientos y responder ante posibles amenazas"77.

Por último, la digitalización de la economía ha conseguido un cambio en todos los sectores económicos; particularmente se han creado las bien conocidas "economías

\footnotetext{
75 BANCO IBEROAMÉRICANO DE DESARROLLO. "Disrupción exponencial en la Economía Digital".2017 Banco Interamericano de Desarrollo BID.

76 "Bitcoin es una moneda: tal como lo es el dólar, el euro, el yen o cualquier otra moneda local en la que se pueda pensar. Sus usos son exactamente los mismos. Lo que marca una gran diferencia con las llamadas monedas fíat (aquellas emitidas y respaldadas por un banco central) es que no existe de forma física". CRIPTONOTICIAS, "Qué es bitcoin BTC".Recuperado el 10 de junio de 2019 de https://www.criptonoticias.com/criptopedia/que-es-bitcoin-btc/
}

77 AUER, R, \& CLAESSENS, S, "Regulación de las criptomonedas: evaluación de reacciones del mercado" Informe Trimestral del BPI, septiembre de 2018, pág. 17. 
colaborativas". ${ }^{78}$ Estas son plataformas tecnológicas que nacen como "(..) nuevos modelos de negocio relacionados con la economía de consumo colaborativo, donde se ofrecen y comparten recursos infrautilizados con el propósito de racionalizar la dinámica moderna de consumo",79 .

Derechos de autor: La propiedad intelectual PI es uno de los temas más sensibles cuando te toca el asunto de la gobernanza de internet. Hay que reconocer un vínculo indisoluble entre PI y derechos humanos. La posición doctrinaria más recurrente es la que reconocer que la PI per sé es un derecho humano; toda vez que comprende creaciones inherentes a las persona humana En ese mismo sentido la UNESCO afirma que "es evidente que la propiedad intelectual entendida como un derecho humano universal difiere de manera fundamental del concepto de interés económico según el derecho de la propiedad intelectual" $"$.

Reconociendo la dificultad que conlleva conciliar aspectos intelectuales con aspectos netamente económicos, además dada la inexistencia de una única visión por parte de la comunidad internacional, se debe advertir sobre la necesidad de trabajar en un esfuerzo por construir un nuevo instrumento internacional en el contexto iberoamericano que involucre los aspectos culturales, de innovación, científicos y tecnológicos. Un acuerdo regional de cooperación en concurso con la Organización Mundial de la Propiedad Intelectual OMPI y la Organización Mundial del Comercio OMC $^{81}$

La visión que se quiere plantear en cuanto a los aspectos regulatorios de la propiedad intelectual en el ciberespacio no es exclusivamente normativa. Hay un vacío cultural que admite que muchos usuarios infrinjan las reglas de derechos de autor en los

\footnotetext{
${ }^{78}$ Las compañías que funcionan bajo el esquema de economía colaborativa con mayor popularidad son: Uber en el sector de transportes y Airbnb en el sector de hostelería. Este modelo ha generado un impacto importante a nivel económico y social; a tal punto que una regulación general no ha sido posible en la mayoría de países por falta de consenso. Por ahora, se avanzado en los esquemas de fiscalidad. Por ejemplo, en Colombia la ley 1819 de 2016 incluyó a la plataformas digitales como responsables del recaudo y pago del Impuesto al valor agregado IVA.

79 ÁLVAREZ GARCÍA, J; DEL RÍO RAMA, M; DURÁN SÁNCHEZ, A.; MALDONADO ERAZO, C. "Economía Colaborativa: Análisis de la Producción Científica en Revistas Académicas", Revista de Gestáo E Secretariado, No 3, 2016, Pág.4.

${ }^{80}$ ORGANIZACIÓN DE LAS NACIONES UNIDAS PARA LA EDUCACIÓN, LA CIENCIA Y LA CULTURA (UNESCO) "La Propiedad Intelectual como Derecho Humano". Boletín de Derecho de Autor, 2001.

${ }^{81}$ Se considera necesario contar con el concepto de los organismos internacionales rectores en el tema de propiedad intelectual, tanto desde el punto vista de los derechos autor en medios digitales como en el caso de la propiedad industrial, las marcar y patentes, en lo relativo al comercio electrónico.
} 
usos cotidianos de internet, como puede ser el hecho de utilizar una imagen (considerada obra) sin tener la autorización del autor. Las leyes fuertes sancionatorias, en derecho de las TIC, no son efectivas si no se acompañan de una estrategia de cultura digital. Algo paralelo ocurre con el uso de las redes sociales, las cuales

$$
\begin{aligned}
& \text { “(...) han promovido la intensificación las relaciones de interacción y } \\
& \text { comunicación entre las personas, circunstancia que ha llevado a los } \\
& \text { gobiernos a cuestionarse sobre el alcance y suficiencia de la } \\
& \text { regulación aplicada a internet; en este caso a las redes sociales, dados } \\
& \text { los riesgos y amenazas para los usuarios”82. ÁREVALO \& } \\
& \text { NAVARRO, 2011:111) }
\end{aligned}
$$

De otro lado, la economía creativa o ahora “economía naranja”, es una industria foco en lo relativo al comercio electrónico, debido a que la mayoría de sectores que la integran, incluyendo principalmente a los jóvenes consumidores, hacen una presencia notoria a través de internet. ${ }^{83}$ De igual manera, si se examina en términos de valor económico actual, la economía naranja equivaldría a la tercera mayor economía de las américas, al séptimo mayor exportador de continente y la cuarta fuerza laboral ${ }^{84}$.Esta economía de experiencia y del conocimiento merece toda la atención de las múltiples partes interesadas.

Principios aplicados a la CIDDI: Como marco amplio de referencia, en el proceso de formación del instrumento iberoamericano de derechos y deberes digitales, se propone la prevalencia del siguiente conjunto de principios: Libertad y neutralidad de la red, legalidad, privacidad, corresponsabilidad, veracidad, respeto mutuo, seguridad, igualdad jurídica, cooperación, sostenibilidad, trabajo colaborativo y publicidad. ${ }^{85}$

\footnotetext{
82. ARÉVALO MUTIZ, P.; NAVARRO HOYOS, J. ; GARCÍA LEGUIZAMÓN, F.; CASAS GÓMEZ, C. (2011). "Modelos de Regulación Jurídica de las Redes Sociales Virtuales". Revista VIA IURIS, No 11, Bogotá, 2011, pág. 111.

${ }^{83}$ La Economía Naranja comprende "Los sectores en los que el valor de sus bienes y servicios de fundamenta en el propiedad intelectual: arquitectura, artes visuales y escénicas, cine, diseño editorial, investigación y desarrollo, juegos y juguetes, moda, música, publicidad, software, Tv y radio, y videojuegos". BUITRAGO RESTREPO, F., \& DUQUE MARQUEZ, I. "La Economía Naranja una Oportunidad Infinita. Banco Interamericano de Desarrollo". Banco Interamericano de Desarrollo, Bogotá, 2013, pág. 15.

${ }^{84}$ Entrevista a DUQUE, IVÁN, "Economía Naranja" por: TV, ASIPI, 2015.

${ }^{85}$ Otro principio que se considera primordial para este propósito común es del de "construir sobre lo construido". Tener en cuenta la primacía del derecho internacional y las experiencias valiosas, lo que en la nueva arquitectura de la cooperación internacional se denominan "buenas prácticas", replicables. Del mismo modo, la difusión (publicidad) es un factor determinante del éxito. Retomando la propuesta del
} 
Finalmente, en los aspectos relativos a la nueva ciberdelincuencia (suficientemente expuestos anteriormente), se debe señalar que es necesario abordar la problemática de manera holística en los ámbitos normativos, culturales y tecnológicos en la región iberoamericana. El fortalecimiento de una ciudadanía digital capaz de contraer derechos y asumir obligaciones. "En este contexto de innovación tecnológica, es obligado preguntarse si el desarrollo de las TIC está generando empoderamiento real en la ciudadanía" ${ }^{\prime 86}$.Este razonamiento reflexivo conduce a la imperiosa necesidad de implementar eficazmente acciones por parte del ciudadano digital del siglo XXI.

\section{CONCLUSIONES}

Así como la tecnología avanza, particularmente en lo relativo al internet, de la misma forma deben progresar los mecanismos que procuran su efectiva gobernanza. Los riegos derivados de las actividades en el entorno digital pueden ser mitigados mediante la creación de un marco normativo "soft law" democrático basado de las responsabilidades, derechos y obligaciones que deben asumir todos y cada uno de los ciudadanos digitales (usuarios de la red). La pretensión no se extiende a crear una constitución universal, pero si a la formación de un mecanismo regional con proyección intercontinental.

La cooperación internacional está llamada a jugar un papel protagónico frente a los desafíos que se derivan del auge de las TIC. El péndulo actualmente se mueve en el debate de regulación, autorregulación, entandares y códigos de conducta; la eficacia es el principio que debe prevalecer.

Se propone la instrumentación para crear una carta iberoamericana de derechos y derechos digitales CIDDI. Esto es, un acuerdo multipartita despojado de un carácter eminentemente técnico y positivista, hacia un carácter cultural y educativo de construcción colectiva y consuetudinario. Se acude al modelo de múltiples partes interesadas, que convoca a todos los actores del ecosistema digital.

profesor Mockus de que cualquier norma debe contener explícitamente el lema indicativo de "Publíquese, Explíquese, Compréndase y Cúmplase". (UNIANDES, 2019).

${ }^{86}$ CÁCERES, M. D., BRANDLE, G., \& RÚIZ, J. A. "Hacia la construcción de una Ciudadanía Digital Nuevos Modelos de Participación y Empoderamiento a través de Internet". Prisma Social Revista de Ciencias Sociales, 2015, p.652. 
La construcción de la carta en el espacio iberoamericano responde a existencia de una identidad iberoamericana, por su historia y sus avances en plano de la cooperación cultural, así como la existencia de una estructura institucional de apoyo. La CIDDI indiscutiblemente constituiría un impulso al cumplimiento de los Objetivos de Desarrollo Sostenible y a la agenda 2030; en lo que se refiere al uso de las TIC y su incidencia en el desarrollo humano, por ejemplo en términos de conectividad.

La CIDDI se propone como un ente vivo sujeto a permanente revisión, adecuación y actualización. Caminando a la par de los desarrollos tecnológicos. Asimismo, la CIDDI sirve como insumo para la potencializar los principios democráticos y las libertades en el espacio iberoamericano. La educación y la cooperación regional se sobreponen al modelo tradicional sancionatorio del Ius puniendi.

La Carta es la semilla para una red independiente; un insumo para la cooperación técnica y la cooperación sur sur. Aprender de las experiencias y de las buenas prácticas de los países avanzados en cuanto a gobernanza digital, por ejemplo España y Portugal como miembros de la Unión Europea y responsables del cumplimiento del reglamento general de protección de datos personales.

Los aspectos centrales del acuerdo tienen que ver con la adecuada protección del derecho a la privacidad, datos de carácter personal y su transferencia internacional, ciberdelincuencia, seguridad de la información y seguridad informática, bancarización y economía digital (comercio electrónico), derechos de propiedad intelectual (derechos de autor y propiedad industrial). Todos estos fenómenos constitutivos del inicio de la cuarta revolución industrial. Las redes sociales son un punto cardinal. Como advierte Habermas: "Es posible que con el tiempo aprendamos a usar las redes sociales civilizadamente". (BORJA, 2018).

Existen dos actores fundamentales: La academia y los medios de comunicación. La academia por la tarea de incluir en el currículo aspectos relacionados con las nuevas tecnologías, los derechos y sus deberes como usuarios. El derecho educativo puede apoyar este propósito. Y por último, los medios de comunicación, en su obligación de proveer información veraz. Los dos se conjugan en el objetivo de implementar mecanismos de pedagogía para dar a conocer los alcances de la CIDDI. 
Revista Electrónica Iberoamericana http://www.urjc.es/ceib/
ISSN: $1988-0618$

Vol. 13, No. 2, 2019 \begin{tabular}{l|l} 
Universidad \\
Rey Juan Carlos
\end{tabular}$\left|\begin{array}{l}\text { Centro de Estudios } \\
\text { de liberomenticas }\end{array}\right|$ ceib

Entre tanto, la CIDDI contribuye a revitalizar el sistema de integración eurolatinoamericano; el cual aún navega en el escepticismo, debido a su ralentización en mecanismos integracionistas de tipo económico. En definitiva, de lo que se trata es generar impactos positivos en la sociedad de la información, ojalá en un futuro próximo hablar de ciudadanos digitales iberoamericanos.

“promúlguese, explíquese y cúmplase”. 


\section{BIBLIOGRAFÍA}

ACUARIO DEL PINO, S. (s/f). Delitos Informáticos: Generalidadea. Recuperado el 20 de Mayo de 2018, de https://www.oas.org/juridico/spanish/cyb_ecu_delitos_inform.pdf

ALFONSO, L. (2016). La Sociedad de la Información, Sociedad del Conocimiento y Sociedad del Aprendizaje. Bibliotecas Anales de Investigación, 12(2), 235-243.

ALMONACID, V., \& SANCLIMENT, X. (2016). El impacto de las TICen la configracuón clásica del Derecho. Especial referencial al principio de territorialiedad. CEF(4), 11-32. Recuperado el 2019 de Mayo de 30, de file://C:/Users/heidy/Downloads/Dialnet-

ElImpactoDeLasTICEnLaConfiguracionClasicaDelDerech-6159600.pdf

ÁlVAREZ GARCÍA, J., DEL RÍO RAMA, M., DURÁN SÁNCHEZ, A., \& MALDONADO ERAZO, C. (2016). Economía Colaborativa: Análisis de la Producción Científica en Revistas Académicas. Revista de Gestáo en Secretariado, 1-21.

ARÉVALO MUTIZ, P., NAVARRO HOYOS, J., GARCÍA LEGUIZAMÓN, F., \& CASAS GÓMEZ, C. (2011). Modelos de Regulación Jurídica de las Redes Sociales Virtuales. Revista VIA IURIS, 109-135.

ARÉVALO, M., \& RAMOS, R. (2018). La Comptencia Mediática de la Ciudadanía en Medios Digitales Emergentes. Prisma Social Revista de Investigación Social(20), 333-346.

AUER, R., \& CLAESSENS, S. (2018). Regulación de las Criptomonedas: evaluación de reacciones del mercado. Informe trimestral del BPI, 1-17.

AYLLON, B. (2015). La Cooperación Sur-Sur en América Latina y Caribe. De una epoca dorada a una fase incierta. Anuario de Integración 11, 134-169.

BALDASSARE, P. (2014). Soft Law y las Teorías de las Fuentes del Derecho. Soft Power, 1(1), 75-89.

BANCO IBEROAMÉRICANO DE DESARROLLO. (2017). Disrupción exponencial en la Economía Digital. Banco Interamericano de Desarrollo BID. 
BENAVIDES, M. A. (2016). La Construcción del Derecho Internacional, el sueño de un reducto jurídico occidental. Revista Colombiana de Derecho Internacional, $10-48$.

BORJA, H. (2018). CULTO. Obtenido de Jurgen Habermas: "Es posible que con el tiempo aprendamos a manejar las redes sociales civilizadamente": ww.culto.latercera.com

BUITRAGO, F., \& DUQUE, I. (2013). La Economía Naranja una Oportunidad Infinita. Banco Interamericano de Desarrollo .

BUSTOS, E. (s/f). La Tercera Ola de Alvin Toffler. Obtenido de Academia.edu: https://www.academia.edu/37797927/La_Tercera_Ola_de_Alvin_Toffler

CÁCERES, M. D., BRANDLE, G., \& RÚIZ, J. A. (2015). Hacia la construcción de una Ciudadanía Digital Nuevos Modelos de Participación y Empoderamiento a través de Internet. Prisma Social Revista de Ciencias Sociales, 643-684.

CALDUCH, R. (1991). Relaciones Internacionales. Madrid: Ediciones Ciencias Sociales.

CASTRO, A. (2018). Gobernanza de Internet . Obtenido de Universidad Externado de Colombia: https://miriadax.net/web/gobernanza-deinternet/reto?p_p_id=activityViewer_WAR_liferaylmsportlet\&p_p_lifecycle $=0$ $\& p \_p \_s t a t e=$ normal $\& p \_p \_$mode $=v i e w \& p \_p \_c o l \_i d=$ column$1 \& p \_p \_c o l \_p o s=2 \& p \_p \_c o l \_c o u n t=3 \& p \_r \_p \_564233524 \_a c t I d=197720 \& p \_r$. p_564233524_moduleId=82331\&p

CENTRO LATINOAMÈRICANO DE ADMINISTRACIÓN PARA EL DESARROLLO (CLAD). (2019). El Centro Latinoamericano de Administración para el Desarrollo, CLAD, es un organismo público internacional, de carácter intergubernamental. Recuperado el 31 de Mayo de 2019, de CLAD: https://www.clad.org/acerca-de/clad

CHIANI, A. (., \& SCARTASCINI, J. (. (2009). La Cooperación Internacional: herramienta clave para el desarrollo de nuestra región. Buenos Aires: Konrad Adenauer Stiftung.

COMISIÓN ECONÓMICA PARA AMÉRICA LATINA Y EL CARIBE (CEPAL). (2019). Agenda 2030 para el Desarrollo Sostenible. Obtenido de Comisión 
Económica para América Latina: https://www.cepal.org/es/temas/agenda-2030desarrollo-sostenible

COMISIÓN EUROPEA. (2019). ¿ Qué rige el reglamento general de protección de datos? (RGPD). Obtenido de La comisión y sus prioridades, políticas información y servicios: https://ec.europa.eu/info/law/law-topic/dataprotection/reform/what-does-general-data-protection-regulation-gdpr-govern_es

COMUNIDAD ANDINA. (2019). ¿Qué es la Comunidad Andina? Obtenido de Comunidad Andina: http://www.comunidadandina.org/Seccion.aspx?id=189\&tipo=QU\&title=somos -comunidad-andina

CONFERENCIA DE MINISTROS DE JUSTICIA DE LOS PAÍSES IBEROAMÉRICANOS (COMJIB) . (s/f). ¿Qué es? Obtenido de COMJIB: https://comjib.org/comjib/

CONFERENCIA DE MINISTROS DE JUSTICIA DE LOS PAÍSES IBEROAMÉRICANOS \& SECRETARÍA GENERAL IBEROAMÉRICANA. (04 de Junio de 2014). Países iberoamericanos firman en Madrid convenio y recomendación sobre ciberdelincuencia. Recuperado el 20 de Mayo de 2018, de https://www.segib.org/paises-iberoamericanos-firman-en-madrid-convenio-yrecomendacion-sobre-ciberdelincuencia/

CONSEJO EUROPEO. (23 de Noviembre de 2001). Convenio sobre la Ciberdelincuencia Budapest - Serie de Tratados Europeos No 185. Recuperado el 30 de Mayo de 2019, de Consejo Europeo: https://www.oas.org/juridico/english/cyb_pry_convenio.pdf

CORREDOR, G. (2015). Consolidación de la Economía Digital y Desafíos en materia de protección de la privacidad . Revista de Derecho, Comunicaciones y Nuevas Tecnologías , 1-26.

CORTE CONSTITUCIONAL DE COLOMBIA. (2005). Capacidad Jurídica, Capacidad de Derecho o de Goce, Capacidad de Hecho o de Ejercicio. Obtenido de Sentencia C-534/05: http://www.corteconstitucional.gov.co/relatoria/2005/C-534-05.htm 
CRIPTONOTICIAS. (2019). Qué es bitcoin BTC. Obtenido de https://www.criptonoticias.com/criptopedia/que-es-bitcoin-btc/

CUMBRE JUDICIAL IBEROAMÉRICANA. (s/f). Estudio de Recomendaciones sobre Ciberdelincuencia. Recuperado el 30 de Mayo de 2019, de Cumbre Judicial: https://www.google.com/search?q=ESTUDIO+DE+RECOMENDACIONES+S OBRE+CIBERDELINCUENCIA\&oq=ESTUDIO+DE+RECOMENDACIONE $\mathrm{S}+\mathrm{SOBRE}+\mathrm{CIBERDELINCUENCIA \& aqs}=$ chrome..69i57.658j0j7\&sourceid $=\mathrm{c}$ hrome \&ie $=\mathrm{UTF}-8$

DÍAZ DÍAZ, I. \&. (s/f). Ciberdelincuencia. (M. d. Gracia, Ed.) Recuperado el 25 de Noviembre de 2018, de RedIberoaméricana: http://www.redipd.org/actividades/seminarios_2008/common/102008/doc_4_2.p df

DÍAZ, C. (2013). Algunas reflexiones sobre la identidad en el seno de la Comunidad Iberoamericana de Naciones. Investrigación y Desarrollo, 419-454.

DIAZ, C., \& ROMERO, M. (2008). Elementos de análsis para la integración de un espacio iberoamericano: economía, política y derecho. Madrid: Plaza y Valdés S.A.

DUQUE, I. (2015). Economía Naranja. (A. TV, Entrevistador)

GALINDO, F. (2012). Democracia, internet y gobernanza: una concreción. Sequencia (Florianópolis)(65), 33-65.

GARCÍA, M. (08 de Octubre de 2015). TIC como un derecho humano. Recuperado el 10 de Junio de 2019, de https://tecnotool.com/tic-como-derecho-humano/

INTERNET SOCIETY . (2016). Gobernanza de Internet: Por qué funciona el enfoque de múltiples partes interesadas. Obtenido de Internet Society: https://www.internetsociety.org/wp-content/uploads/2016/04/IGMultiStakeholderApproach-ES.pdf

JIMÉNEZ, W., \& MENECES, G. (2017). Derecho e Internet; Introducción a un campo emergente para la Investigación y práctica Jurídica. Prolégomenos Derechos y Valores, II, 43-61. 
KATZ, R. (.-c. (2015). El ecosistema y la economía digital en América Latina. (y. F. Barcelona: Ariel, Ed.) Obtenido de Comisión Económica para América Latina y el Caribe.

MASON ANALYSYS. (2017). Expansiòn de la Banda Ancha Moviel Elinimación de barereras para la expansión de la banda ancha movil a nivel subnacional. Buenos Aires: Corporación Andina de Fomento.

MINISTERIO DE TECNOLOGÍAS DE LA INFORMACIÓN Y LA COMUNICACIÓN (MinTic). (2019). ONU y MinTIC organizan primera conferencia sobre contextos jurídicos de Economía Digital en Latinoamérica. Obtenido de Ministerio de las Tecnologías de la Información y las Comuniaciones: https://www.mintic.gov.co/portal/604/w3-article-101006.html

MOLANO, D. (2019). ¿Cómo llegamos al mundo Digital? Obtenido de Banco Interamericano de Desarrollo.

ORGANISMO INTERNACIONAL DE JUVENTUD PARA IBEROAMÉRICA. (s/f). OIJ. Recuperado el 20 de Mayo de 2019, de https://oij.org/codei/

ORGANIZACIÓN DE LAS NACIONES UNIDAS PARA LA EDUCACIÓN, LA CIENCIA Y LA CULTURA (UNESCO). (2001). La Propiedad Intelectual como Derecho Humano. Obtenido de Boletín de Derecho de Autor.

ORGANIZACIÓN DE LAS NACIONES UNIDAS PARA LA EDUCACIÓN, LA CIENCIA Y LA CULTURA (UNESCO). (2 de Septiembre de 2013). Universalidad de Internet: un medio para crear sociedades del conocimiento y la agenda de desarrollo sostenible después de 2015. Obtenido de UNESCO: http://www.unesco.org/new/fileadmin/MULTIMEDIA/HQ/CI/CI/pdf/news/inter net_universality_es_01.pdf

ORTEGA, A., DOMENECH, \& José. (2018). Nuevo marco jurídico en materia de protección de datos de caracter personal en la Unión Europea. Revista de la Facultad de Derecho(44), 1-35.

PIANA, R. (2010). Las Cartas Iberoamericanas para una Gestión Pública de Calidad. Orientaciones y buenas prácticas. Revista Aportes para la Integración Latinoamericana(23), 23-63. 
RAMÍREZ, J. (s.f.). Las Tecnologías de la Información y las comunicaciones - TIC como herramientas de desarrollo económico y su impacto en la herradicación de la pobreza extrema y Hambre. Obtenido de Colegio Mayor de Nuestra Señora del Rosario: https://www.urosario.edu.co/Tic-Tank/inicio/\#

RED IBEROAMÉRICANA DE PROTECCIÓN DE DATOS. (2017). Estándares de Protección de Datos Personales para los Estados Iberoamericanos. Recuperado el 2019 de Junio de 07, de Red Iberomericana de Protección de Datos: http://www.redipd.org/noticias_todas/2017/novedades/common/Estandares_Esp _Con_logo_RIPD.pdf\#Testo\%20en\%20espa $\% \mathrm{C} 3 \% \mathrm{~B} 1 \mathrm{ol}$

REMOLINA, A. (s/f). Latinoamérica y Protección de Datos Personales en Cifras (1985-2014). Obtenido de Universidad de los Andes: https://habeasdatacolombia.uniandes.edu.co/wp-content/uploads/2014Latinoamerica-proteccion-datos-en-cifras-1985-2014-Remolina.pdf

REMOLINA, N., \& ALVAREZ, L. (2018). Guia GECTI para la implementación del principio de responsabilidad demostrada -accountability-en las transferencias internacionales de datos personales. Universidad de los Andes, Facultad de Derecho GECTI.

RICHTER, M. (2015). La Protección de Datos de Caracter Personal como Derecho Humano. Revista Auctoritas Prudentium, 18-29. Obtenido de Revista Auctoritas Prudentium.

SANIN, J. (2015). Tributación de la economía digital; perspectivas desde el derecho internacional. Revista Instituto Colombiano de Derecho Tributario(72), 233248.

SECRETARÍA GENERAL IBEROAMÉRICANA . (s/f). La Cooperación iberoamericana. Recuperado el 30 de Mayo de 2019, de Secretaría General Iberoaméricana: https://www.segib.org/cooperacion-iberoamericana/

SECRETARÍA GENERAL IBEROAMÉRICANA. (2015). Quienes Somos. Recuperado el 30 de Mayo de 2019, de Secretaría General Iberoaméricana: https://www.segib.org/quienes-somos/ 
SECRETARÍA GENERAL IBEROAMÉRICANA. (2018). Recursos Digitales en Iberoamérica: una agenda accesible. XXVI Cumbre Iberoaméricana La Antigua Guatemala 2018 (págs. 1-26). Secretaría General Iberoaméricana.

SECRETARÍA GENERAL IBEROAMÉRICANA. (2019). SEGIB. Obtenido de Quiénes somos: https://www.segib.org/quienes-somos/

SECRETARÍA GENERAL IBEROAMÉRICANA. (s/f). Balance de la Cooperación Iberoamericana. Recuperado el 20 de 11 de 2018, de Secretaría General Iberoaméricana: https://segib.org/wp-content/uploads/Balance-cooperacion-ibcastellano.pd

SECRETARÍA GENERAL IBEROAMÉRICANA. (s/f). SEGIB EL Espacio Iberoamericano La Comunidad de todos. Obtenido de Secretaría General Iberoaméricana: https://segib.org/wp-content/uploads/Espacio-IberoamericanoOOII-CAST.pdf

SECRETARÍA PERMANENTE CUMBRE IBEROAMÈRICANA. (2017). Ciberseguridad. Recuperado el 30 de Mayo de 2019, de Secretaría Permanente Cumbre Iberoamèricana: http://www.cumbrejudicial.org/ejusticia/ciberseguridad

SORIA, R. E. (2013). El Derecho Educativo en el Mundo Jurídico. Catamarca: Libook.

UNIANDES. (2019). Pedagogía legislativa y política: una tarea pendiente en Colombia. Obtenido de Congreso Visible Universidad de los Andes: https://congresovisible.uniandes.edu.co/agora/post/pedagogia-legislativa-ypolitica-una-tarea-pendiente-en-colombia/150/

UNIÓN INTERNACIONAL DE TELECOMUNICACIONES (ITU). 2010, p. 9. (2010). Ciberseguridad. En UIT, Actualidad de la UIT, haciendo referencia a la Resolución 181 del mismo organismo.

UNIÓN INTERNACIONAL DE TELECOMUNICACIONES. (2010). Ciberseguridad. Actualidad de la UIT, haciendo referencia a la Resolución 181 del mismo organismo., 20-22. Obtenido de Unión Internacional de Telecomunicaciones: https://www.itu.int/net/itunews/issues/2010/09/pdf/201009_20-es.pdf

VELASCO, C. (2011). Territorialidad, extraterritorialidad e interés. InDret REVISTA PARA EL ANÁLISIS DEL DERECHO, 1-56. 
VENGOA, H. (2004). La Globalización. Relaciones Internacionales, entre lo global y lo local. Ediciones TADEO.

VERA, J. M. (2009). Las Cumbres y la Cooperación Iberoamericana. Razón y fe: Revista hispanoamericana de cultura, 63-74.

XXI CUMBRE IBEROAMERICANA PARAGAY 2011 \& SECRETARÍA GENERAL IBEROAMERICANA. (2011). Anexo del Programa de Acción de Asunción Resultados de la Cooperación Iberoamericana- Resultados de los Programas, Iniciativas y Proyectos Adscritos de Cooperación Apoyados por la Cumbre Iberoamericana. Obtenido de Secretaría General Iberoaméricana : https://www.segib.org/wp-content/uploads/Resultados_Programas_Anexo-PAESP.pdf 